\title{
Observaciones sobre la publicación del Diccionario crítico etimológico de la lengua castellana de Joan Coromines
}

\author{
JOSÉ IGNACIO PÉREZ PASCUAL \\ Universidade da Coruña
}

El examen de la correspondencia cruzada entre los intelectuales de nuestro reciente pasado puede proporcionar al estudioso una valiosa información no solo acerca de su trayectoria vital, sino, muy especialmente, acerca de su labor científica; tal sucede en el caso de Joan Coromines, que no constituye excepción. ${ }^{1} \mathrm{El}$ análisis de su epistolario ha servido con anterioridad para reconstruir su quehacer filológico (vid. Pascual y Pérez Pascual 2003 y 2006; Pérez Pascual 2007); en esta ocasión, he querido complementar trabajos previos y atender a un aspecto digno de atención, pero en el que no había podido demorarme: ${ }^{2}$ me refiero al proceso de publicación del Diccionario crítico etimológico de la lengua castellana (en adelante DCEC), cuando, casi finalizada la redacción, todavía hubo Coromines de afrontar muchos problemas.

\section{LA REDACCIÓN DEL $D C E C$}

Desde su llegada a la Universidad de Mendoza, Coromines comenzó la lectura y estudio de cuanto estuvo a su alcance sobre el léxico castellano; hasta mediados de 1946 fue despojando de manera sistemática los libros y revistas más importantes. Así, cuando se incorporó a la Universidad de Chicago, aunque quedaban muchos cabos sueltos, pudo comenzar en los primeros días de 1947 la redacción del $D C E C$, labor a la que se consagró durante otros siete años; ${ }^{3}$ era un trabajo de tales dimensiones que le obligaba a reservar todos los minutos a esa labor, aun a costa de descuidar ciertos convencionalismos sociales:

${ }^{1}$ Vid. Ferrer (2005). Utilizamos en este artículo la correspondencia intercambiada por el filólogo con un buen número de colegas; hemos preferido no eliminar algunos comentarios de Coromines y de sus corresponsales, pues tales supresiones enturbiarían una correcta comprensión de las difíciles circunstancias en que se tuvo que desenvolver la filología española durante la postguerra.

Dado que Coromines es el emisor o receptor de todas las cartas citadas, indicamos en el caso de las inéditas quién es su corresponsal y la fecha de la misiva (y, si está publicada, añadimos la oportuna referencia bibliográfica). Con el fin de facilitar su lectura, desarrollamos abreviaturas y truncamientos y colocamos entre corchetes algunas aclaraciones. Buena parte de las cartas inéditas figurarán en un próximo volumen que ultimo, publicado bajo los auspicios de la Fundació Pere Coromines, en el que se recogerán los intercambios epistolares entre Coromines y algunos destacados filólogos españoles que permanecieron en España tras la Guerra Civil (Dámaso Alonso, Rafael Lapesa, Julio Casares...); otros volúmenes habrán de compilar la extensa correspondencia que cruzó con tres figuras señeras que concluyeron sus vidas lejos de España: Tomás Navarro, Américo Castro y Amado Alonso.

${ }^{2}$ Apenas pudimos reservarle un par de páginas en Pascual y Pérez Pascual (2006: 53-54).

${ }^{3}$ Para un examen detallado del proceso, vid. especialmente Pascual y Pérez Pascual (2003 y 2006); incluimos información detallada acerca de los plazos en la redacción en Pascual y Pérez Pascual (2006: 47-52). Es una tarea que, insistirá en ello muchas veces, consagró a una lengua que no le era querida: «aquesta obra a la qual hauré dedi- 
Perdone mi retraso en contestarle. Usted imaginará que escribiendo anualmente un millar de páginas del diccionario sin abandonar la enseñanza a full-time, y a razón de tres cursos trimestrales por año, debo tener abandonada la correspondencia y aun trabajar día y noche (carta a Lapesa, 27.2.1948).

En el mismo sentido escribe poco antes a Ferran Cuito ${ }^{4}$ y Tomás Navarro («Trataré de escribirle más a menudo, aunque preveo que el diccionario me va a tener muy absorbido en los 3 próximos años», carta a Navarro, 6.8.1947) o se dirige a Américo Castro, en una reveladora carta fechada apenas tres meses después de haber iniciado la redacción:

Mucho he tardado en escribir el artículo baratar, y por ello en contestar a su amabilísima carta. Espero que sea usted indulgente con mis razones. [...] Ahora la cuestión es que pueda terminar la obra. Al paso que llevo tengo para 3 años por lo menos. En adelante podré acelerar pues ya tengo completo el fichero fechador que he tenido que ir haciendo, y la masa enorme de mis papeletas (más de 200.000), ha quedado ordenada [...]; mas por otra parte también me veré obligado a reducir a lo normal mi horario que hasta aquí ha sido de 10 y 12 horas diarias, si no quiero caer enfermo. Llevo escritas 140 páginas como estas que ve usted. [...] De nuevo perdone usted mi retraso y silencio. Y perdone que no le hable de otros asuntos: debo seguir escribiendo el libro (carta a Castro, 9.3.1947; incluyo el texto completo de la misiva como anexo I). ${ }^{5}$

Trabajando de este modo, en enero de 1947 empezó a redactar los diferentes lemas. Su tarea comenzaba por organizar cuanto se había dicho sobre las voces que tenía delante - información volcada en cientos de carpetillas-, sometiéndolo a crítica y concluyendo en una propuesta explicativa; preparaba así a máquina una primera redacción de los artículos que, con el paso del tiempo, iría incrementando con infinidad de adiciones manuscritas. Al finalizar el $D C E C$, pasó a limpio ese difícil original, al que volvió a añadir un buen número de correccio-

cat els millors anys de la meva vida, però que està consagrada a una llengua que no puc estimar cordialment. És veritat que la llengua catalana hi és citada a cada pàgina i gairebé a cada ratlla, i és veritat que provo indiscutiblement que centenars de mots castellans són manllevats a la nostra llengua. Però això què hi fa si al capdavall serà sempre un llibre dedicat al castellà? Tanmateix vaig comprometre'm a escriure aquesta obra abans de tornar a Catalunya, $\mathrm{i}$ això li explicarà la meva impaciencia per acabar-la, i començar la redacció de l'obra catalana parl-lela, els materials complets de la qual vaig recollir al mateix temps que els de l'altra des de 1939 a 1946» (carta a Cuito, 28.8.1947, Coromines 2008b: 338-339); «em dol d'haver hagut de dedicar al castellà una part tan gran de la meva vida, encara que el llibre és ple de qüestions de lingüística catalana, i encara penso pendre una revenja catalanista en el próleg» (carta a Batista i Roca, 27.3.1953, Coromines 2009: 35-36).

${ }^{4}$ «Estic avergonyit d'haver trigat mig any a contestar a la seva amable carta del febrero. La meva única excusa és que des d'aleshores estic fent un esforç intensíssim, al mateix temps que prossegueixo el meu ensenyament en aquesta Universitat, per escriure el meu Diccionari etimológic castellà, obra enorme que estic preparant des de 1939 i de la qual ja tinc escrit l'original de 580 pagines impreses en $4^{\circ}$, corresponents a una sisena part del total de l'obra (lletres $A$ i $B$ ) [...]. Haver escrit en set mesos les pàgines que li dic és un esforç aclaparador, que solament puc fer a costa d'interrompre totalment la meva correspondencia» (carta a Ferran Cuito, 28.8.1947, Coromines 2008b: 338339).

${ }^{5}$ En otro lugar he de ocuparme del modo en que Coromines incorpora al DCEC algunas hipótesis etimológicas que Américo Castro le hace llegar, contraviniendo en este punto los deseos de su antiguo profesor. 
nes en la revisión final, con las que enviará un texto, no demasiado pulcro, a la imprenta (y aún realizará no pocos cambios en pruebas). ${ }^{6}$

El vertiginoso proceso de redacción de una obra de tamañas dimensiones obedecía al temor de que el proyecto quedase inacabado: frente a la deseable — e inalcanzable — perfección, se conformaba el filólogo catalán con dar fin a un buen diccionario o, incluso, uno mediano; por ello, reitera una y otra vez en la correspondencia su convicción de que el $D C E C$, una vez concluido, precisaría de muchas enmiendas:

tengo plena conciencia de que el difícil empeño en que estoy metido me obliga a abordar problemas sumamente espinosos y a veces insolubles o poco menos. Aun cuando no logre resolverlos, me consuelo pensando que, por lo menos, los acerco a la solución, gracias al método de escudriñar a fondo e imparcialmente todos los datos fundamentales y no callar ninguno, aunque no sea o no parezca favorable a mis ideas (carta a Menéndez Pidal, 10.9.1950, Coromines 2006: 232).

En ponderado juicio de Porto Dapena, aunque no tuviéramos en cuenta su restante obra, «sólo por su Diccionario crítico etimológico hay que considerar a D. Juan Corominas uno de los más insignes filólogos españoles [...] de todos los tiempos», pues proporcionó «a nuestra lengua un instrumento fundamental y prácticamente definitivo en materia etimológica: en verdad se trata de una obra que tan solo ha sido superada por ella misma en una nueva versión» (2000: 121). Mas lo cierto es que, a pesar de las dificultades y limitaciones con las que se enfrentó Coromines, acabó proporcionando en el DCEC muchísimo más de lo que en un principio prometía su autor (vid. Pascual y Pérez Pascual 2006: 18); e incluso de lo que resultaba imaginable: ${ }^{7}$ tanto como para que haya servido a los hispanistas durante décadas como sustituto de un diccionario histórico, aunque no fuera este el fin con que se concibió. En efecto, los modestos datos léxicos que Coromines había allegado con la intención de arropar la argumentación etimológica dan cuenta de la historia de un buen número de voces, ofreciendo de este modo una información más propia de un diccionario histórico que de uno etimológico. Ya en 1947 señala a Américo Castro que

Tras el signo va la fecha de la primera edición del vocablo, y aquí es más provisional todo, el signo y la fecha misma pues nadie mejor que usted sabe lo atrasados que están esta clase de trabajos para el castellano, tan adelantados en francés, inglés y alemán (los hados han querido que el fichero del Centro de Estudios Históricos no haya de poder utilizarse en mi obra, y sobre todo cuando se terminen los dos tomos publicados del Diccionario Histórico de la Academia, el de Autoridades me servirá de muy poco; pero creo que es mejor esto que nada, y que así daremos un primer paso; claro que no me limito a los Diccionarios de la Academia, sino que consulto los glosarios de autores y tengo a la mano Alonso de Palencia, Nebrija, Pedro de Alcalá, tendré

\footnotetext{
${ }^{6}$ No está de más reconocer la decisiva importancia que tuvieron los editores en el resultado final del $D C E C$, sin perder la paciencia con una obra tan difícil, compleja y abierta a correcciones de última hora. En otro lugar habremos de comparar la redacción primitiva de algunos artículos y su versión definitiva.

${ }^{7}$ «El resultado muy positivo con que nos atrevemos a valorar esta obra se ha logrado combinando un método riguroso con no poco ingenio e imaginación, aparte del apoyo insustituible de una bibliografía magníficamente seleccionada. En un trabajo de esta envergadura, que contiene más problemas que palabras acoge, realizado además en condiciones nada favorables, un exceso, un error o incluso un disparate, no se puede tomar como piedra de toque de su calidad, de su interés o de su importancia. Su solidez tiene que ver con la búsqueda — y logro- de interpretaciones razonables, no con la inexistencia de desaciertos» (Pascual y Pérez Pascual 2006: 45).
} 
Oudin, y además tengo una infinidad de fichas que he hecho estos años, de casos de aparición temprana de vocablos) (carta a Castro, 9.3.1947).

Todo ello convierte el DCEC en el mejor instrumento filológico con que contamos todavía para la explicación de los textos del pasado; según ha observado Gregorio Salvador: «tenemos [...] un Diccionario etimológico, el de Corominas, que suple hasta donde puede esa carencia [de un diccionario histórico]. [...]. Su Diccionario no es [...] una historia de la lengua, pero la historia de la lengua está allí̀ (1985: 147-148).

\section{LA BÚSQUEDA DE UN EDITOR}

A finales de abril de 1950, Menéndez Pidal se interesaba por la marcha del diccionario:

hace mucho deseaba escribirle, deseando saber noticias de su gran obra del Diccionario que sin duda abrirá una larga época en los estudios etimológicos. [...] ¿Por qué letra va usted? ¿Cuánto tiempo puede calcularse que falta todavía? (carta de Menéndez Pidal, 30.4.1950, Coromines 2006: 229-230).

En esa ocasión se anima incluso a proponer a su discípulo su edición en España («hemos de tratar de publicarlo aquí, por si resulta más beneficioso para usted, como es muy probable», carta de 30.4.1950, Coromines 2006: 231). Coromines le respondió meses después que estaba ya redactando el comienzo de PI- y que «En un año más termino: tengo todos los cálculos detallados hechos hasta el final y no me puedo equivocar en esta previsión si la salud no me flaquea (y por ahora la disfruto excelente) o no ocurre alguna catástrofe general» (carta a Menéndez Pidal, 10.9.1950, Coromines 2006: 233), situación confirmada por otra epístola de esas mismas fechas: «El meu diccionari arriba a PI-; compto acabar-lo l'estiu que ve» (carta a Sanchis Guarner, 21.9.1950, Coromines 2006b: 43). Pensando ya en la posible publicación, anticipa las dimensiones previstas del $D C E C$, con un cálculo muy preciso:

Para un cálculo provisional, quizá necesario antes de hacer una oferta de publicación, puede hacer falta indicar que mi diccionario tendrá 4.500 páginas a máquina, con el texto a doble espacio y las notas sin espaciar [...]. Hasta ahora llevo escritas 3.300 de estas páginas, pero las adiciones marginales equivalen casi a la mitad de otro tanto (carta a Menéndez Pidal, 10.9.1950, Coromines 2006: 240).

Todavía no había contraído el filólogo catalán ningún compromiso para la edición de una obra de semejante envergadura, aunque informa a don Ramón de la existencia de dos ofertas, la de «un editor suizo importante y serio» ${ }^{8}$ y la del Servicio de Publicaciones de la Universidad de Chicago, si bien «ninguna de las dos es firme todavía: están estudiando el asunto y creo que resolverán en pocas semanas». ${ }^{9}$ En ese momento le parece más ventajosa la oferta de Chicago, que «sólo depende de una subvención especial que quieren obtener»; sin embargo, temía que el elevado coste de la impresión en Estados Unidos se pudiese traducir en

${ }^{8}$ Se trata de la editorial Francke, como aclarará en una carta posterior (carta a Menéndez Pidal, 30.3.1951, Coromines 2006: 244).

${ }^{9}$ Menciona también una «propuesta argentina muy vaga, que no creo siga adelante» (carta a Menéndez Pidal, 10.9.1050, Coromines 2006: 239). 
que el $D C E C$ resultase «prohibitivo para los europeos y sudamericanos y así se perdería gran parte de los beneficios que pueden esperarse de mi libro para la investigación futura», por lo que se resistía a aceptar la propuesta de su propia universidad («Realmente preferiría no hacerlo si no me veo obligado, pero quizá sea forzoso», carta a Menéndez Pidal, 10.9.1950, Coromines 2006: 239) ${ }^{10}$. Por ello, Coromines no descarta por completo la posibilidad de publicar el $D C E C$ en España, «de la cual me habla usted» ${ }^{11}$, aunque puntualiza que para ello precisaría

recibir una propuesta concreta y le agradecería hondamente lo que pueda usted hacer en este sentido cuanto antes se pueda, pues no hay que olvidar la amenaza de una guerra general, larga y dura, que suspenda esta clase de publicaciones por mucho tiempo (carta a Menéndez Pidal, 10.9.1950, Coromines 2006: 239).

Además, las especiales circunstancias políticas españolas contribuyen a que se muestre reticente:

la publicación en España me da ciertas inquietudes, sobre todo una: según me dice el Sr. Gili, una vez logrado el efecto de propaganda que interesaba a los dirigentes, han escaseado los créditos para la publicación de su Tesoro: ¿no pasaría lo mismo a mi libro? (carta a Menéndez Pidal, 10.9.1950, Coromines 2006: 240). ${ }^{12}$

Y de un modo sutil, trata de comprometer a Pidal en la decisión: «A pesar de todo, si usted me lo aconseja, no vacilaré en decidirme por la publicación en España» (carta a Menéndez Pidal, 10.9.1950, Coromines 2006: 240).

Don Ramón trató de hacerle ver que las circunstancias políticas estaban cambiando en nuestro país - son los años de un tímido aperturismo, representado en el plano educativo y científico por la figura de Joaquín Ruiz-Giménez como Ministro de Educación-y que incluso existía la posibilidad de que el exiliado pudiese retornar a su patria y ocupar una cátedra universitaria; además, lo animaba a no renunciar a la edición del DCEC en España:

${ }^{10}$ En el mismo sentido se dirige a Sanchis Guarner: «Un cop publicat el diccionari, m'interessa com al qui més que sigui accessible als hispanistes, és a dir, que es vengui a un preu mòdic. Per això resistiré tant com pugui a una publicació en els EE.UU.; solament m'hi decidiria si la Universitat de Xicago ho encomanava a un impressor europeu i es comprometia a vendre'l barat. Si s'imprimeix i edita a Suïssa, ja hi haurà poca diferència amb Espanya» (carta a Sanchis Guarner, 19.12.1950, Coromines 2006b: 58).

${ }^{11}$ En realidad, es el propio Coromines quien ha insinuado esa posibilidad un año antes: «No sé si habría interés por parte de alguien en que mi diccionario se publicara en España. Si es así, conviene no tardar. La Universidad de Chicago adquiere cierto derecho moral a publicar mi diccionario si empiezo, en junio próximo, a aprovecharme de los 3 meses anuales de vacaciones extraordinarias, pagadas, que me conceden. Ya recibí de la University Press una propuesta preliminar de publicación. Por suerte hasta ahora no piden respuesta. Claro está que este aspecto no es de interés personal mío, y no sé que piensa usted del caso. Mi impresión personal es que valdría más publicarlo aquí, pero no me opondría a hacerlo en España si hay buenas razones» (carta a Menéndez Pidal, 11.1.1949, Coromines 2006: 224).

${ }^{12}$ Alude al Tesoro lexicográfico de Samuel Gili Gaya, cuya publicación se inició en 1947 pero se demoró grandemente y se interrumpió definitivamente en 1957, tras la aparición del cuarto fascículo (letras D-E). También hace referencia a la suerte del Tesoro en su correspondencia con Sanchis Guarner, quien precisamente en esos momentos está iniciando su colaboración con el CSIC para la finalización del Atlas Lingüistico de la Península Ibérica (en adelante $A L P I$ ): «I allí [en Suiza] no hi ha el perill que la impressió s'eternitzi com està passant amb el Tesoro d'En Gili i Gaya?» (carta a Sanchis Guarner, 19.12.1950, Coromines 2006b: 58). 
Si quiere usted venir al nuevo Instituto Cervantes del que yo soy Presidente (no sé si me limitaré a serlo honorario o si me animaré a intervenir más) y del que es Director efectivo Casares, podrá usted ahí seguir publicando su Diccionario Etimológico. Lapesa, Dámaso Alonso podrán informarle a fondo (carta de Ménendez Pidal, 19.2.1948, Coromines 2006: 195-196).

Pero aunque el deseo de obtener una cátedra en España nunca se cumplirá, ni tendrán lugar algunos de los proyectos acariciados — la colaboración en el Diccionario histórico —, la negociación sobre la publicación del $D C E C$ circula por sendas más firmes, especialmente desde que queda clara su desvinculación del regreso de Coromines:

En cuanto a la publicación del Diccionario, la aceptación es también indudable. Ya sabe usted lo del Atlas de Navarro ${ }^{13}$ para el cual fui a visitar al Ministro de Asuntos Exteriores [Alberto Martín Artajo], quien dio inmediatamente las órdenes para que se le facilitasen los dólares necesarios para que los colaboradores vayan a entrevistarse con Navarro. Conceder dólares ahora es sumamente difícil y ve usted que hay buenas disposiciones. Si después se embarrancan las cosas como [Samuel] Gili [Gaya] dice ¿quién puede asegurar nada? Evidentemente el Consejo Superior [de Investigaciones Científicas] tiene mucho desorden con las imprentas, pero esto creo sea remediable (carta de Menéndez Pidal, 10.10.1950, Coromines 2006: 242-243).

De hecho, probablemente como resultado de las gestiones de Menéndez Pidal, Manuel Sanchis Guarner, aprovechando su viaje a Nueva York con vistas a la reanudación de las labores del $A L P I$, hace llegar a Coromines una propuesta confidencial del CSIC:

També havia de trametre-us un missatge del Consell d'Investigacions Científiques, però un missatge confidencial i que no us l'hauria acabat d'exposar, si en començar a parlar-ne, veia que no us interesaba. Vós fa anys que em coneixeu i sabeu com m'ha tractat En Franco, i no hi ha la perill que em considereu com un agent seu que fa la propaganda entre els exiliats perquè retornen. Desprès d'aquest preàmbul tan enfarfegat entraré en matèria. Sabem per diversos conductes, especialment En Bassols de Climent, que vàreu parlar de retornar a Barcelona si us asseguraven 4.000 pts. mensuals, quantitat que En Bassols trobava excesiva. En Balbín, vicesecretari de Publicacions del Conselll d'Investigacions a Madrid, diu que si no teniu cap comprimís editorial sobre el vostre diccionario, que el Consell d'Investigacions l'editaria amb molt de gust, que durant el temps que necessitàsseu per acabar-lo i la seva publicació, us pagarien la mensualitat que voldríeu encara que fos superior a la denegada per En Bassols, que residiríeu a Madrid en la residència d'investigadors amb la vostra familia per evitar-vos el problema de trobar habitació. A més això el Consell exerciria la seva influència perquè sortís a oposició una càtedra que us pogués interessar, i àdhuc va parlar de proveir la cátedra de Filologia catalana de la Universitat de Barcelona. [...] Si us interessàs poc o molt, al meu retorn a Espanta a mitjan Febrer pordien formalitzar-se les relacions (carta de Sanchis Guarner, 13.12.1950, Coromines 2006b: 51-53).

Sin embargo, son condiciones que no satisfacen a Coromines en lo que hace referencia a su posible futuro profesional:

${ }^{13}$ Aunque ya desde 1910 Menéndez Pidal acariciaba la idea de redactar el ALPI, será en los años veinte cuando comiencen los trabajos de este ambicioso proyecto inspirado por don Ramón y dirigido por Tomás Navarro, quien preparó el cuestionario y adiestró al equipo que realizó la mayor parte de las encuestas entre 1931 y 1936 (véase Pérez Pascual 1998: 256-259, 1999, 2007b, 2007c y 2008, trabajos que se integran en una serie que habrá de contener al menos otras dos entregas hoy en preparación). 
La proposta que em transmet cada vegada és menys temptadora ${ }^{14}$ perquè ara el diccionari ja s'està acabant i ells no es comprometen més que fins a la fi del diccionari; la meva obra jo no solament vull que es publiqui sinó que la seva publicació s'acabi de pressa. Si volen que jo vagi a Madrid han de fer-me un oferiment en ferm per a després del diccionari. I aquesta oferta me l'han de fer directament i per escrit. Vostè ja comprèn que jo no em puc fiar d'ells en altra forma (les condicions que li van dir a vostè no són les que jo demanava). [...] Tornant a l'oferiment que em transmet. El que cal és que me'n facin un o altre en ferm, per escrit i directament. Encara que no sigui el que jo voldria. M'ho pensaré i decidiré. [...] Desitjo tornar. Tanmateix no de qualsevol manera. I si no és en forma molt satisfactoria, serà per a anar a Barcelona, naturalment; no pas a Madrid (carta a Sanchis Guarner, 19.12.1950, Coromines 2006b: 56 y 58).

Tiene Coromines serias dudas de cuáles son los intereses reales del CSIC: si verdaderamente quieren contar con él o si simplemente pretenden apuntarse el tanto de la publicación del $D C E C ;{ }^{15}$ además, tampoco está dispuesto a someterse a ningún tipo de censura científica y, por ello, inquiere a Sanchis Guarner:

Ells tenen la tradició de voler esmenar els originals que publiquen. El parer que li demano és: no creu que voldrien fer el mateix amb el meu? I jo no admetria cap esmena, passat que fossin millores, pero millores que m'ho semblessin a mi. Un dels millors editors europeus de lingüística em proposa publicar el diccionari: un suís. Em sembla que em decidiré a acceptar-ho. Creu que a Madrid tenen tant d'interès a publicar-me el llibre? Potser valdria més que no hi insistissin (carta a Sanchis Guarner, 19.12.1950, Coromines 2006b: 57).

Tan solo admitiría una revisión por alguien que le mereciese respeto y cita el nombre de Menéndez Pidal: «Una revisió per part d'ell no em preocuparia i seria útil fins i tot. Però no seria ell qui la faria, i allà no hi ha ningú més de qui m’interessi l'opinió» (carta a Sanchis Guarner, 19.12.1950, Coromines 2006b: 58); ya había indicado anteriormente al propio don Ramón que únicamente estaba dispuesto a someter el $D C E C$ a su evaluación:

En cuanto al carácter personal del diccionario, claro es que la revisión de usted, en cuanto le sea posible favorecerme con ella, es algo que deseo y acepto como el mejor beneficio para mi obra. Por otra parte no veo en España a nadie más a quien pueda aceptar como juez perito en la materia (carta a Menéndez Pidal, 8.3.1948, Coromines 2006: 201).

No tarda Sanchis Guarner en despejar algunas de las dudas de Coromines: «Segons les impressions prèvies que tinc, són favorables totalment a les vostres condicions. No els preocu-

\footnotetext{
${ }^{14}$ En realidad, ya había recibido una proposición muy semejante en lo sustancial casi tres años antes, a instancias de Menéndez Pidal: «Ya hablé con Casares de esto y necesitamos saber qué cree usted necesario para vivir aquí. Podría usted vivir en la Residencia del Consejo Superior de Investigaciones Científicas, Pinar 21, muy cómodamente instalada y barata, donde admiten matrimonios. Diga usted lo que además del pago de la residencia necesitaría usted para decidirse a venir, y creo podría proporcionársele. [...] En la Residencia tendría usted buenas habitaciones. El precio no nos interesa ahora saberlo, pues ya lo añadiremos aquí a lo que usted nos diga que necesita además de casa y mesa» (carta de Ménendez Pidal, 19.2.1948, Coromines 2006: 195-196).

${ }^{15}$ «En tot cas m'interessa de saber si el que ells desitgen és comptar amb la meva col-laboració allà per a les tasques de l'Institut Cervantes, o si en el que estan interessats és en la publicació del diccionari. Qualsevol informació o impressió que voste pugui donar-me sobre aquest punt tindrà per a mi la més gran importancia» (carta a Sanchis Guarner, 19.12.1950, Coromines 2006b: 57-58).
} 
pa que combateu García de Diego ni el Consell revisa mai cap original, i això explica, encara que no justifiqui, que n'hagi publicat de tan dolents!». Quedaba pendiente, sin embargo, «concretar si la vostra relació s'havia de limitar al Diccionari o bé si havíeu d'ésser membre de l'Institut Cervantes. A més cal començar el diàleg per escrit directament, i haurem de cercar la fórmula per començar-lo», pero concluía su informe con un optimista «Crec que tot es podrà arranjar» (carta de Sanchis Guarner, 21.3.1951, Coromines 2006b: 65).

\section{LA DECISIÓN}

Finalmente, en marzo de 1951 Coromines da cuenta a Menéndez Pidal de su renuncia a que el $D C E C$ se publique en la Universidad de Chicago ${ }^{16}$ y su opción por la editorial más apropiada en aquel momento, la suiza Francke, que, a instancias de Jud, parecía decidida a editar su monumental obra lexicográfica:

Hace un par de semanas he recibido una oferta de publicación de mi diccionario por parte de A. Francke A.G., de Berna, el editor que publica actualmente el FEW [Französisches Etymologisches Wörterbuch] de [Walter von] Wartburg, el Indogermanisches Etymologisches Wörterbuch de [Julius] Pokorny, y otras obras lingüísticas de no menor importancia. Bien puede decirse que Francke es hoy unos de los primeros editores de Lingüística en el mundo; casa seria y responsable (carta a Menéndez Pidal, 30.3.1951, Coromines 2006: 244).

La propuesta es muy tentadora en el plano científico, pero también en el económico, pues la editorial no solo se compromete a publicar el DCEC «a un precio incomparablemente más accesible para todo el mundo que el que aquí [en Chicago] habrían exigido (hablaban de 60 dólares o más cada tomo)», ${ }^{17}$ sino que ofrece al autor «un tanto por ciento apreciable, y por lo pronto un anticipo, que en el cambio actual viene a ser como de 1.250 dólares o más de 60.000 pesetas» (carta a Menéndez Pidal, 30.3.1951, Coromines 2006: 245). ${ }^{18}$

No obstante, el filólogo catalán deja todavía abierto un resquicio a una posible oferta desde España y confiesa que ya habría aceptado la oferta suiza

si no recordara que el Instituto Cervantes ha manifestado alguna vez, aunque en términos muy vagos, la intención de publicarlo, y que usted mismo se me ofreció a gestionar que se publicara en España [...]. Un ruego de usted no podría dejar de hacerme impresión (carta a Menéndez Pidal, 30.3.1951, Coromines 2006: 245-246).

De hecho, aunque Coromines se inclina a aceptar la propuesta de Francke en la seguridad de que de este modo se garantiza al DCEC una esmerada edición, ${ }^{19}$ decide posponer su

\footnotetext{
${ }^{16}$ «Como la University Press ya me ha dicho que ellos no pueden competir con esta oferta, y por su parte comprenden que yo dé la preferencia a Francke, supongo que las autoridades universitarias me contestarán lo mismo y me dejarán en libertad de publicar en Suiza» (carta a Menéndez Pidal, 30.3.1951, Coromines 2006: 245).

${ }^{17}$ Entre otros detalles, la editora le indica que han previsto una tirada de 3000 ejemplares, a un precio de cuarenta francos el tomo, si bién más adelante ( $c f$. infra) Coromines se referirá a una tirada de solo 2000.

${ }^{18}$ Francke se compromete a anticipar 5000 francos a cuenta de los derechos de autor (un $10 \%$ sobre la primera mitad de la tirada y un $15 \%$ sobre la segunda).

${ }^{19}$ «he notado que los caracteres fonéticos y otros son a menudo muy defectuosos en las últimas impresiones españolas» (carta a Menéndez Pidal, 30.3.1951, Coromines 2006: 246).
} 
respuesta un mes, hasta finales de abril, a la espera de alguna solicitud española, que «sólo lograría hacerme impresión si fuese acompañada por una oferta de colocación técnica en España, rodeada de todas las garantías de seriedad y permanencia, y con buenas condiciones económicas» (carta a Menéndez Pidal, 30.3.1951, Coromines 2006: 246). Además, en esa misma carta incide en que su regreso a España debería quedar desvinculado de la posible publicación del $D C E C .^{20}$

Pidal se apresura a contestar antes de que venza el mes de abril y expone a su discípulo que ha tratado el asunto con Rafael de Balbín, director del Instituto Miguel de Cervantes del CSIC, quien le ha asegurado que el Consejo podría ofrecerle condiciones similares a las de Francke, aunque le confiesa que con vistas a una más amplia difusión le parece mejor la edición en Suiza; en todo caso, deja claro a Coromines que puede decidir con toda libertad, pues «la cuestión del Diccionario queda independiente de la de su regreso a España, tal como usted deseaba» (carta a Coromines, 23.3.1951, Coromines 2006: 249-250). ${ }^{21} \mathrm{~A}$ la vista de las palabras bienintencionadas y sinceras de su maestro, opta Coromines por la oferta de Francke, en las mismas fechas en que da por concluida la redacción:

Acabo de terminar el Diccionario. El texto está completo hasta el último artículo. Faltan ahora los índices y la bibliografía, que deseo hacer muy completos [...]. También falta todavía corregir la copia que ha hecho un alumno mío de una parte del original que había quedado demasiado llena de añadiduras y enmiendas para poderla entregar directamente al impresor; esta copia está también terminada (carta a Menéndez Pidal, 11.11.1951, Coromines 2006: 251). ${ }^{22}$

Coromines se mostraba en ese momento confiado en el éxito de las negociaciones con la editorial, pues era consciente de estar dando remate a un producto lexicográfico de gran calidad. Y es que, a medida que ha progresado la redacción del $D C E C$, se siente cada vez más seguro de su labor y, ante los tímidos indicios de apertura en el régimen franquista, concibe esperanzas de poder regresar a España; por ello solicita a su maestro

un esfuerzo para lograrme la recompensa que me ofreció al invitarme a acometer la durísima tarea que he dejado terminada. Empecé el diccionario joven y lo he acabado envejecido prematuramente por un esfuerzo que no sin razón califica Jud de «inhumano». Once, doce y a veces quince horas de trabajo fueron mi pan cotidiano durante los últimos años. Todo con la esperanza de volver a España. Me reconforta pensar que los ofrecimientos de usted no eran vanos (carta a Menéndez Pidal, 13.5.1952, Coromines 2006: 268).

${ }^{20}$ «No por esto renuncio a la idea de volver a la patria. Pero creo que sería mejor [...] desglosar la publicación del libro, de la cuestión de mi regreso. Creo que lo que yo puedo dar con mi enseñanza universitaria, o con mi labor técnica en una institución dedicada a la Lingüística o a la lexicografía científica es algo de valor bastante alto para que deban desearlo por sí solo, sin la añadidura de la publicación de mi libro (que al fin y al cabo quizá dé poco rendimiento económico). [...] creo preferible que mi regreso sea deseado por lo que vale, y se separe de la publicación del libro» (carta a Menéndez Pidal, 30.3.1951, Coromines 2006: 246).

${ }^{21} \mathrm{Y}$ añade: «He hablado largo de sus problemas con Balbín quien ha escrito a usted ya sobre su regreso, garantizándole (lo que ahora puede garantizarse) la estancia aquí mientras se prepara la cátedra conveniente y la oposición».

${ }^{22}$ «En el diccionario tengo todavía mucho que hacer corrigiendo la copia en limpio, y puliendo y unificando el estilo, siglas de citas, etc. Al mismo tiempo estoy haciendo los índices y recopilando la bibliografía, muy copioso uno y otro. Espero terminar antes de que embarque en abril» (carta a Menéndez Pidal, 24.12.1951, Coromines 2006: 257). 
Merecen un estudio pormenorizado los fracasados intentos de reintegrar a Coromines a la universidad española y en otro momento habremos de ocuparnos con detalle de las esperanzas que durante algún tiempo acaricia el catalán y que se reflejan con mucha frecuencia en su correspondencia de aquellos años. ${ }^{23}$ Lo cierto es que durante su primer viaje a España tras un largo exilio, en mayo de 1952, cree incluso posible imponer ciertas condiciones para su regreso y señala a don Ramón su deseo de optar a una cátedra en la Universidad de Barcelona, sin que ello signifique abstenerse de «colaborar con los trabajos de Madrid»:

Si por ejemplo se considerara que puedo ayudar poderosamente al Diccionario Histórico de la Academia, lo haría con gusto y en Barcelona podría hacerlo bien, que no en Chicago. La enseñanza universitaria deja libres cuatro o cinco meses al año: estaría muy dispuesto a pasar todo este tiempo en Madrid, y aun a trabajar en Barcelona el resto del año en los originales que se me enviaran por correo. Suponer que un erudito que ha hecho una obra de las proporciones de mi Diccionario pueda en el futuro desinteresarse de la Filología castellana, quedaría fuera de lo razonable (carta a Menéndez Pidal, 13.5.1952, Coromines 2006: 266-267). ${ }^{24}$

En el mismo sentido, y de modo casi idéntico, escribe a Dámaso Alonso pocos meses después:

después de escribir estos trece tomos de original de mi Diccionario, como el que vio usted, es ridículo pensar que yo pueda desinteresarme o descuidar la filología castellana en el resto de mi vida. Y si en algo puedo ser útil para la obra filológica que se realiza en Madrid, doce horas en tren o tres de avión no son obstáculo para que pueda trasladarme [...] tantas veces al año como convenga. Sí lo es el tener que vivir en Chicago. Si yo lograra ganar una cátedra en Barcelona, y se considerara útil mi presencia en Madrid, desde luego empeño mi palabra de pasar ahí los cuatro meses de vacaciones veraniegas, y cuantas semanas del resto del año me dejase libre la Universidad de Barcelona (carta a D. Alonso, 14.8.1952). ${ }^{25}$

Sin duda la colaboración de Coromines en la elaboración del $D H$ habría sido muy positiva, pues el proyecto académico proseguía su dificultosa — y extremadamente lenta — redacción: «esperamos lanzar los primeros fascículos en 1955, algo como unas 300 páginas. Mucho confiamos en la ayuda que nos prestará el Diccionario Etimológico de usted, cuya aparición inmediata se anuncia ya y del que tan excelentes muestras se han dado a conocer» (carta de Lapesa, 16.9.1954). De hecho, el filólogo catalán había prestado ya su puntual colaboración cuando lo habían solicitado los responsables del $\mathrm{DH}$, como se desprende de algunas de las cartas que intercambia con Julio Casares, quien había proyectado ese ambicioso intento lexicográfico y lo dirigió hasta su fallecimiento:

${ }^{23}$ Baste en este momento, casi a modo de ilustrativo ejemplo, remitir a las cartas que Coromines cruza con Rafael Lapesa y Julio Casares, que he incluido como anexo II; en ellas se nos ofrecen además valiosas apreciaciones sobre los dos ambiciosos proyectos lexicográficos, el DCEC y el Diccionario histórico (en adelante $D H$ ).

${ }^{24}$ Lo cierto es que, una vez publicado el $D C E C$, seguirá vinculado al castellano, sobre todo con la revisión de su magna obra etimológica $(D C E C H)$, pero estas tareas se nos antojan secundarias con respecto a lo que consideraba su labor principal, el trabajo en el dominio del catalán.

${ }^{25}$ Incluyo el texto completo de la carta, muy revelador, como anexo III. 
A propósito de la duda abarrisco o a barrisco y del problema etimológico que suscita, he recordado la promesa de ayuda que usted me hizo. No tengo que decirle que cualquier información con que usted nos favorezca la tendremos por estrictamente confidencial hasta que se publique su Diccionario, cosa que ocurrirá mucho antes de que vea la luz nuestro primer fascículo. En nuestra obra citaremos la procedencia de las etimologías cuando no se trate de las tradicionales y consabidas, o de las discurridas por nosotros, que serán muy escasas, de conformidad al criterio que ya expuse en mi Introducción (carta de Casares, 14.10.1952).

Recibí oportunamente su atenta carta [...] y en mi nombre y en el del Seminario le agradezco la convincente información que nos comunica acerca de a barrisco. No será ciertamente la última vez que le molestemos por el mismo motivo (carta de Casares, 14.11.1952).

El filólogo catalán era consciente de que su retorno a la universidad española se vuelve cada vez más difícil:

Les negociacions continuen, potser no conduiran enlloc. Les grans promeses que feren quan es tractava de decidir-me a escriure el meu Diccionari Etimològic Castellà és probable que no es compleixin mai, com sempre he temut; de més a més sembla que s'indignen perquè, ara que el tinc acabat, no els el vull lliurar perquè el publiqui el Consejo Superior de Investigaciones Científicas; ells poden faltar a les seves promeses però jo miraré de treure de la publicació del 1libre els diners que pugui publicant-lo en una altra banda (carta a Nicolau d'Olwer, 15.12.1952, Coromines 2008: 49).

Puede incluso apreciarse en sus epistolarios que Coromines consideraba que se estaba faltando a las promesas que se le habían hecho (incluso por parte de Menéndez Pidal) y que concebía el DCEC como una contrapartida que en cierto modo se le había exigido como pago para obtener la deseada cátedra en su patria:

Les gestions per obtenir una càtedra a la Universitat de Barcelona han resultat infructuoses malgrat de les grans promeses de Menéndez Pidal i l'esforç gairebé sobrehumà d'escriure el meu Diccionario crítico etimológico de la lengua castellana [...]; em dol d'haver hagut de dedicar al castellà una part tan gran de la meva vida (carta a Batista i Roca, 27.3.1953, Coromines 2009: $35-36){ }^{26}$

De todos modos, ni sus tentativas de volver a España ni las negociaciones con distintas editoriales lograron ralentizar el ritmo de trabajo del filólogo, de suerte que, de acuerdo con sus propias previsiones, pudo escribir a don Ramón en noviembre de 1951: «Acabo de terminar el Diccionario. El texto está completo hasta el último artículo» (carta a Menéndez Pidal,

\footnotetext{
${ }^{26}$ Pueden seguirse con bastante claridad sus intentos de retornar a España en la correspondencia con Menéndez Pidal, su principal valedor (vid. Coromines 2006: 185-292). Coromines se resigna a no incorporarse a la universidad española - y no se aprecian nuevas menciones a este hecho en la correspondencia con Menéndez Pidal - a partir de su participación en el Congreso de Barcelona; lo cierto es que, según escribió a su hermano Albert, tras su intervención denunciando la persecución al catalán, «Certs col·legues m’han fet avinent que m’havia barrotat la 'càtedra que ja tenia segura en una universitat espanyola'; jo me'n ric perquè sé molt bé que ningú no pensava donar-me tal càtedra, i altrament era una obligació fer el que vaig fer i espatllar-los aquesta farsa» (Coromines 2003: 42, n.). Con todo, parece que hubo una verdadera intención de ayudarlo por parte de algunos de sus colegas españoles; vid. la carta a Dámaso Alonso incluida como anexo III.
} 
11.11.1951, Coromines 2006: 251). Con todo, quedaba todavía bastante trabajo, pues el filólogo catalán, como ya hemos indicado, había ido incorporando a la primera redacción, mecanografiada en apretadas páginas, una cantidad similar de información en adiciones manuscritas $\mathrm{y}$, aunque un colaborador se ocupaba de pasar a limpio esos papeles, era imprescindible revisar y corregir el trabajo; había convenido en un principio con la Universidad de Chicago «que en cuanto llegue por la $\mathrm{P}$ o la $\mathrm{R}$ ellos me proporcionarán un mecanógrafo experimentado en trabajos filológicos (ya lo tengo puesto a prueba) que copie en limpio el original, de modo que la composición tipográfica pueda empezar el mismo día en que yo termine la redacción de la $Z_{\text {» }}$ (carta a Navarro, 24.8.1949). ${ }^{27}$ Pensaba terminar todo ello antes del mes de abril de 1952, pero se retrasó un poco y dio cima a la obra a finales de agosto de $1952 ;^{28}$ faltaban tareas menores que le llevarían escaso tiempo, como confeccionar la bibliografía y redactar el prólogo (Coromines 2006: 277-278). Según el propio autor reconoce, la conclusión del diccionario «ha costado un esfuerzo enorme, que en algún tiempo he temido acabase con mi salud», pero de todos modos «la obra es grande y valía la pena» (carta a Menéndez Pidal, 11.11.1951, Coromines 2006: 251).

Al recibir el anuncio de la conclusión del $D C E C$, don Ramón responde a vuelta de correo, felicitando con entusiasmo a su discípulo, ${ }^{29}$ pero no deja de incidir en la necesidad de que se apresure a imprimir su magna obra: «Habrá ahora que procurar la pronta publicación para que no se atrasen las partes impresas al comienzo. ¡Se trabaja tan activamente en ese campo!» (carta de Pidal, 16.11.1951, Coromines 2006: 253). Y lo cierto es que un buen número de sus corresponsales van a insistirle también en la necesidad de editar cuanto antes una aportación científica que, a la luz de los adelantos dados a conocer por su autor, se les antojaba de la mayor necesidad en el panorama hispánico; en este sentido se manifiestan en su correspondencia filólogos de la categoría de Américo Castro, Julio Casares o Rafael Lapesa:

${ }^{27} \mathrm{Y}$, en efecto, «al único auxiliar que la Universidad ha puesto a mi disposición le tengo ocupado en la copia en limpio de algunas páginas de mi original que habían quedado demasiado llenas de adiciones manuscritas; quiero que esta tarea termine al mismo tiempo que la redacción de la Z, con el fin de evitar todo retraso en el comienzo de la impresión del libro» (carta a Menéndez Pidal, 10.9.1950, Coromines 2006: 234-235). «También falta todavía corregir la copia que ha hecho un alumno mío de una parte del original que había quedado demasiado llena de añadiduras y enmiendas para poderla entregar directamente al impresor; esta copia está también terminada. En cuanto tenga unos centenares de páginas corregidos los mandaré a Francke para que empiece la impresión» (carta a Menéndez Pidal, 11.11.1951, Coromines 2006: 251).

${ }^{28}$ En esas fechas puede informar a don Ramón que ha terminado de recopilar «los índices alfabéticos de voces extranjeras, y otros índices útiles: por ejemplo mozarabismos, leonesismos, catalanismos, aragonesismos, portuguesismos, occidentalismos americanos, etc.; de ciertos fenómenos fonéticos y gramaticales importantes y poco estudiados; de arabismos, celtismos, vasquismos, iberismos, indigenismos americanos etc.; de artículos donde se hacen modificaciones o se dan explicaciones importantes a ciertas obras básicas de consulta [...]. Todavía he tenido tiempo de incorporar los resultados de algunos trabajos importantes publicados últimamente y de otros ya publicados antes, de cuya importancia me di cuenta demasiado tarde para la primera redacción [...]. Pero ahora he cerrado ya con carácter definitivo, pues un día u otro había que hacerlo» (carta a Menéndez Pidal, 29.8.1952, Coromines 2006: 277-279). Poco más tarde escribe a Francesc de B. Moll que «l’original esta complet, amb índexs alfabètics i tot, escrit a màquina, i no hi haura addicions ni correccions en el curs de la impressió») (carta a Moll, 19.12.1952, Coromines 2000: 152).

${ }^{29}$ «mi más efusiva enhorabuena [...]. No sabe usted la alegría que me produce el fin de su trabajo, que será elemento de adelanto científico muy duradero» (carta de Menéndez Pidal, 16.11.1951, Coromines 2006: 253). 
¿Cómo va su obra magna? Leí en Vox Romanica la etimología de hazaña, excelente. El año pasado [...] pasé a verle en Chicago y no estaba. [...] hubiera deseado ver más de su diccionario (carta de Castro, 18.8.1951).

Gran noticia saber que el Diccionario está a punto casi de ser impreso. Va a ser buen alivio para todos nosotros (carta de Castro, 16.11.1951).

¿Cuándo la obra magna? (carta de Castro, 27.2.1953).

¿Cuándo empieza a imprimirse su Diccionario? Ya sabe usted que lo esperamos como agua de mayo (carta de Casares, 14.10.1952).

Muy prometedoras son esas muestras del Diccionario Etimológico que todos deseamos aparezca pronto. [...] Y el Diccionario etimológico ¿ha empezado a imprimirse? (carta de Lapesa, 31.5.1953).

\section{CRISIS Y SOLUCIÓN FINAL}

A finales de agosto de 1952 todo parecía resuelto y Francke, que disponía ya de la mitad del manuscrito, incluso había enviado a Coromines muestras de una página impresa que daba una idea cabal de cómo iba a quedar la obra. ${ }^{30}$ Es de suponer la emoción con la que el etimólogo viajó a Berna en septiembre, para ultimar con los editores los detalles de la impresión y entregarles personalmente la segunda mitad del original. Pero se produjo un suceso inesperado: su maestro Jakob Jud, que apoyaba decididamente la publicación, había fallecido el 15 de junio de ese año y la empresa editorial creyó entonces necesario solicitar un informe confidencial acerca del $D C E C$, probablemente a Walter von Wartburg. A pesar de ser positivo, el memorando sugería que el diccionario se podía abreviar considerablemente. Sospechaba Coromines que había podido pesar en el informe el hecho de que

Wartburg y Jud eran muy poco amigos personalmente; hay ahí algo de un rencor entre escuelas rivales, del que temo ser víctima. ${ }^{31} \mathrm{El}$ hecho es que mi libro no puede acortarse, no se puede ma-

\footnotetext{
${ }^{30}$ Remite una de las muestras a Pidal: «Me alegraría saber la impresión que le cause. Creo innovación útil el imprimir las notas en tipos del mismo cuerpo que el texto, pues de otro modo habrían sido difícilmente legibles por la pequeñez, y las notas contienen a veces material tan importante como el texto. Habrá en total unas 3.000 páginas de texto como este. Otra innovación útil creo será la numeración de las líneas, pues hay artículos que llenarán cinco y aun seis páginas cada uno y entonces se hace muy difícil citar con precisión, como ocurre tantas veces con el $F E W$ [Französisches Etymologisches Wörterbuch] de [Walter von] Wartburg. He tenido que librar una batalla para hacer que Francke acepte estos detalles, que encarecen un poco, aunque no mucho, la edición; pero ya ha aceptado, y ya nada entretendrá la impresión» (carta a Menéndez Pidal, 29.8.1952, Coromines 2006: 276).

${ }^{31}$ Puede verse un juicio crítico de Coromines sobre Walter von Wartburg y su obra etimológica en su correspondencia con Josep Pla: «Tant o més que un bon investigador és un docent eficaç i un gran organitzador científic [...]. La història acadèmica dels nostres països occidentals li ha permès i facilitat el que ens ha negat a d'altres: organiztzar un vast equip de col.laboradors ben triats i situats [...]; reconeguem que també ha estat un gran organitzador del seu treball propi, i que ha estat un treballador colossal, herculi, al llarg de la seva llarga vida. Part de la seva obra, i de la que més es maneja, no és gaire solida, i en els seus manuals hi ha sovint oripell i metall de llei dubtosa encara que sempre brillant. La seva única obra sòlida i durable és el diccionari etimològic francès [...], però quina obra! Aquests deu grans volums ja publicats [...] constituiran una pedrera que solament generacions futures de lingüistes arribaran a explotar com cal; ara com ara solament els millors dels seus col.legues en treuren veritable partit, encara que thotom el cita superficialment; es tracta d'una poderosa sinopsi del colossal conjunt de lexicografia de França entera, dialectal, antiga i moderna. La massa dels professors i estudiosos de les llengües romàniques, ara com ara, adopta davant Wartburg i la seva obra una actitud doblement errada: d'una banda en realitat recula peresosament davant la utilització eficaç, directa i crítica d'aquesta mola gegantesca i poc elaborada; d'altra banda, esbalaïda i espa-
} 
terialmente, y aun si se hubiese podido, esta sugestión llegaría demasiado tarde, pues acabo de pasarme un año revisando el texto definitivo, tarea que ya he terminado y que no puedo emprender de nuevo; si lo hiciera sólo serviría para agregar nuevos argumentos y datos que he recogido últimamente, y para retrasar nuevamente la publicación (carta a Menéndez Pidal, 7.10.1952, Coromines 2006: 285).

Coromines rebate por escrito las principales observaciones críticas del informante y, para reforzar su posición, se anima a solicitar de don Ramón «un informe o carta favorable», detallándole aquellos puntos en los que consideraba preciso incidir (carta a Menéndez Pidal, 7.10.1952, Coromines 2006: 285) ${ }^{32}$ El anónimo evaluador había sugerido reducir «a una sola las citas que doy de autores clásicos»; sin embargo, a juicio del filólogo catalán estas abundantes citas eran necesarias al no contar el castellano con un diccionario histórico (es consciente de que el $D C E C$ «llenará provisionalmente una gran laguna durante los cuarenta años largos que se hará esperar»); además, las citas permiten comprobar la pertenencia de cada voz a determinados registros y niveles. ${ }^{33}$

Objetaba también el informante un hecho que ha suscitado igualmente críticas por parte de algunos lectores del $D C E C$ : la existencia de un exceso de «argumentación etimológica», frente al estilo «telegráfico» que caracterizaba, a juicio de Coromines, la obra lexicográfica de Wartburg. Y es que, al afrontar el problema metodológico de exponerlo todo o no hacerlo, Coromines opta por la primera opción, amparándose en la necesidad de la mayor claridad expositiva; ${ }^{34}$ además, si el informante le reprocha demorarse en rechazar opiniones claramente erróneas que no merecían tener cabida en el $D C E C$, el investigador catalán se acoge precisamente a la absoluta necesidad de descartar explícitamente tales juicios trasnochados:

no habría dejado de hacerlo así [omitir esas opiniones erradas] si sólo me dirigiera a lingüistas consumados como usted o como él, pero no se da cuenta de que en el mundo hispanohablante la evidencia de estos errores resulta mucho menor: aun colegas tan prominentes como [Yakov] Malkiel o [Vicente] García de Diego suelen adherirse muchas veces a esos errores, y a otros colegas más inteligentes que estos [...] les sucede otro tanto; si me callara frente a estas opiniones improbables, es seguro que los «críticos» las resucitarían, y de ahí otra vez refutaciones inevita-

terrada per aquest conjunt poderós i d'aparença uniformement brillant, té tendència a pendre com a article de fe les deduccions que Wartburg en treu, sogui en els seus manuals i monografies (sovint molt flacs, com ja he dit), sigui en les conclusions del mateix $F E W$. En realitat aquestes valen molt menys que els materials; Wartburg és home de pensament poc original i poc penetrant, si bé sempre molt hàbil» (carta a Pla, 12.6.1961, Coromines 2001: 45-46).

${ }^{32}$ Menéndez Pidal accedió inmediatamente al requerimiento y remitió a la editorial suiza sus observaciones el 15 de ese mismo mes de octubre; $c f$. Coromines (2006: 285-286, n. 6).

${ }^{33}$ Por otro lado, en el DCEC Coromines había concedido conscientemente preferencia a los datos históricos sobre los dialectales (a diferencia de lo que hacía Wartburg en el FEW) (vid. carta a Menéndez Pidal, 7.10.1952, Coromines 2006: 286).

34 «en 1920 [...] Wartburg [...] constituyó una tradición a la cual se muestra todavía ligado en sus últimos fascículos, aunque ha ido ampliando paulatinamente sus explicaciones en los tomos más recientes del FEW — pero hay todavía mucho sobreentendido, frases equívocas o no bastante claras, argumentos auxiliares callados, y puntos básicos olvidados o sólo aludidos vagamente; y el caso es que, según muestra la experiencia, muchas veces sus colegas y críticos, no dándose cuenta de esos argumentos descuidados, escriben nuevos artículos, y aun buscan etimologías nuevas, de donde interminables polémicas (que no es raro degeneren en personalismos), lo cual se habría evitado con ser más explícito» (carta a Menéndez Pidal, 7.10.1952, Coromines 2006: 287). 
bles, polémicas y balumba erudita innecesaria; preferí rechazarlas someramente, con la esperanza de que así queden enterradas para siempre (carta a Menéndez Pidal, 7.10.1952, Coromines 2006: 287-288).

No fue el de don Ramón el único escrito cursado en apoyo del $D C E C$, pues la editora había solicitado también la opinión de Dámaso Alonso:

Hace pocos días he recibido una carta de la casa Francke en que me pedían un informe sobre su Diccionario Etimológico. Hoy me llega la carta de usted y lo comprendo todo. Es una pena que pequeñas envidias se interpongan en las empresas científicas, y el autor de ese informe verdaderamente no sabe lo que se pesca.

Hoy mismo sale para la casa Francke una carta mía. Le adjunto una copia. [...] Dígame si [...] le parece bien. Si desea usted que la haga más larga o que hable de alguno de los puntos tratados por el otro informante, lo haré con gusto en nueva carta. Esta ha salido para Suiza al mismo tiempo que la presente (carta de D. Alonso, 12.10.1952).

Ciertamente la obra hubiera podido perfeccionarse con una nueva corrección: por un lado, la gran seguridad que había adquirido el etimólogo le permitía contar con nuevos argumentos en su trabajo, aparte de que en ese momento podía disponer de datos que habían estado hasta entonces fuera de su alcance; por otro, permitiría aliviar el texto de bastantes páginas, a la vez que dotarlo de una mayor coherencia. Todo ello habría de redundar, en efecto, en una apreciable mejora del diccionario, pero suponía una larga y enojosa labor de corrección que retrasaría mucho la salida del $D C E C$, contraviniendo frontalmente la decisión del filólogo de construir en el menor tiempo posible un útil instrumento susceptible de posteriores revisiones.

Coromines se muestra confiado en que la editorial acepte sus puntos de vista, aunque lamenta que esté tardando demasiado en tomar la decisión y se muestra incluso dispuesto a sopesar «otras ofertas de publicación que tengo» (carta a Menéndez Pidal, 7.10.1952, Coromines 2006: 289), como confirma en su correspondencia con Tomás Navarro o con Francesc de B. Moll:

Como tengo otros candidatos, soy yo el que me decidiré dentro de uno o dos meses si no acaba aún de decidirse. Ya le tendré a usted al corriente (carta a Navarro, 5.12.1952).

Com que Francke triga molt a pendre la decisió definitiva encara és possible que em decideixi a prescindir-ne i a triar un altre editor, ja que la contribució financera de la Universitat facilitaria molt el problema econòmic (carta a Moll, 19.12.1952, Coromines 2000: 153).$^{35}$

Pero, además, otros motivos retrasaban la decisión definitiva de la editora helvética, como el elevado coste que suponía la impresión de un diccionario de esta envergadura en las imprentas de ese país:

${ }^{35}$ La contribución económica prometida por la Universidad de Chicago garantizaba la colocación inmediata de la mitad de la tirada, ya que esta institución «es quedaria de bon principi 1.000 exemplars a canvi de la distribució exclusiva en els EE. UU i Canada, i Francke vendria directament els 1.000 restants a la resta del món» (carta a Moll, 19.12.1952, Coromines 2000: 152-153). 
Todavía no se ha empezado a imprimir el diccionario: Francke quiere, pero todavía vacila por el coste; parece que va a decidirse de un momento a otro (carta a Navarro, 5.12.1952).

En principi estava decidit l'editor Francke de Berna a publicar el llibre ell i imprimir-lo a Suïssa, pero ara s'inclina a imprimir a Espanya per tal de reduir el cost (carta a Moll, 19.12.1952, Coromines 2000: 152-153).

Por ello, mientras Francke acaba de decidirse, Coromines procura facilitar la resolución del problema buscando en España una imprenta que ofrezca un precio más ajustado que las suizas, pero que cuente con los tipos necesarios para una obra de las características del DCEC y que pueda llevar a cabo el trabajo en solo dos años; en busca de consejo acude a Moll, quien llevaba adelante la publicación del Diccionari català-valencià-balear (en adelante DCVB): ${ }^{36}$

Li ho agrairia molt si em pogués proporcionar la informació següent. Estem cercant un bon impressor a Espanya que pogués imprimir el meu Diccionari etimològic castella; es tractaria d'aconseguir un cost més reduït de la impressió del llibre i per tant poder-lo vendre més barat. El seu diccionari surt ben imprès i l'impressor té si fa no fa tots els caràcters i diacrítics que jo necessitaria per al meu. Creu que podria encarregar-se de la tasca? Me n'alegraria molt si fos així, i tot seguit ens hi posaríem en contacte directe per saber preus; a condició, però, que la impressió es pogués fer sense retards i sense interrupcions, car no voldria esperar més d'un any (o maxim dos) per a la publicació de tot el llibre, [...] segons els càlculs fets per un tecnic suís (amb els quals coincideixen els meus) el llibre omplirà cosa de 3.000 pàgines en $4 .^{\mathrm{t}}$ a dues columnes $\mathrm{i}$ amb unes 60 línies cada una [...]. En principi estava decidit l'editor Francke de Berna a publicar el llibre ell i imprimir-lo a Suïssa, però ara s'inclina a imprimir a Espanya per tal de reduir el cost. [...]. De tota manera, sigui amb Francke o amb un altre, em convindria saber un bon impressor espanyol. Tant si és el de vostès com un altre em farà, docs, molt favor indicant-me'l (carta a Moll, 19.12.1952, Coromines 2000: 152-153).

Moll le informa, sin embargo, que los talleres que se ocupaban del DCVB no podían hacerse cargo en ese momento de un trabajo como el DCEC y le sugiere acudir a la imprenta Roca, que se había encargado de la Gramática histórica catalana de Antoni Ma Badía Margarit. ${ }^{37}$

Finalmente, los problemas se solventaron gracias a la intervención de la editorial Gredos, merced al apoyo decidido de Ramón Menéndez Pidal y de Dámaso Alonso. Fue este último, director de la «Biblioteca Románica Hispánica» de la prestigiosa editora madrileña,

${ }^{36}$ El filólogo mallorquín Francesc de Borja Moll colaboraba desde 1921 con Antoni Maria Alcover en la redacción del $D C V B$, importante obra lexicográfica que prosigue a la muerte de su mentor, en 1932, y que logra sacar adelante a pesar de las dificultades de la postguerra (la publicación, iniciada en 1930, concluyó en 1962).

${ }^{37}$ «He pensat en l'assumpte de la impremta que l'interessa. La del Diccionari no se'n podria encarregar per ara, perque amb els elements de què disposa no dóna l'abast al Diccionari i a les altres coses que ja porta entre mans. Si dins alguns mesos aconseguís augmentar molt el material i maquinaria per a la composiciò (cosa no gens segura ni fàcil), crec que es podria comptar amb aquesta impremta. Ara com ara, el taller que té signes fonètics semblants o potser iguals als del Diccionari és la impremta Roca, de Manresa, que ha imprès la Gramática histórica catalana de Badia. El que no sé és quina capacitat o possibilitats té d'atendre un encarrec com el del Diccionari vostre. Crec que En Casacuberta és molt amic d'aquella impremta, i ell es podria informar millor que jo d'aqueixes circumstàncies. Podríeu posar uns mots a En Casacuberta explicant-li el caràcter de l'obra, i ell segurament us faria la gestió previa informativa» (carta de 16.1.1953, Coromines 2000: 155-156). En todo caso, no se conservan cartas de estas fechas con Josep Maria Casacuberta, lo que parece un indicio de que Coromines no intentó esta vía. 
quien sugirió en primer lugar la posibilidad de que la empresa española participase en esta aventura editorial:

mi deseo mayor sería que su diccionario se imprimiera en España, y la editorial Gredos lo haría inmediatamente sin más condición que la de la ayuda de la Universidad de Chicago, en la misma forma que según me dijo usted se acordó para la editorial suiza: la editorial Gredos estaría conforme también — si la Universidad de Chicago lo prefería - en aparecer como mera co-editora junto con la mencionada Universidad. El coste del libro en España sería seguramente mucho menor que en Suiza. La canalización de ejemplares dentro del mundo hispánico sería mucho mayor — por el coste más bajo-; y fuera del mundo hispánico se vendería lo mismo (por lo menos). Es lástima.

Crea usted, pues, que me ha dolido tener que escribir esa carta [el informe favorable al DCEC]: pero lo he hecho porque usted me lo pedía y era estricta justicia. [...] Con la esperanza de que todo se le arregle conforme a sus deseos (aunque en lo de la edición los nuestros sean distintos) (carta de D. Alonso, 12.10.1952).

De este modo, a principios de 1953 se iniciaron las gestiones para que Gredos llevara el peso de la edición, en colaboración con Francke. No obstante, las negociaciones no avanzaban con la rapidez que Coromines deseaba y ello le lleva a impacientarse y solicitar nuevamente el concurso de don Ramón y de Dámaso Alonso:

Los tratos para la publicación de mi diccionario se prolongan lamentablemente, y bien sin mi culpa, como verá usted si tiene tiempo para leer la carta que incluyo. Es para Dámaso Alonso. [...] tengo entendido que Alonso está por salir de Madrid y temo que ya lo haya hecho (sería, creo, para varios meses). Esto causaría un gran retraso a la recepción de mi carta, que espero termine con la paralización de las negociaciones. Le pido, pues, que si Alonso está ya ausente la transmita usted a la Editorial Gredos (carta a Menéndez Pidal, 3.2.1953, Coromines 2006: 291).

La respuesta de Dámaso Alonso evidencia que por esas fechas todavía no se había cerrado el acuerdo entre la editorial suiza y la española («Hace mucho que recibí su carta, y mucho que debía haber contestado. Quería ver si en este tiempo me llegaban noticias de Gredos con algo decisivo que les hubiera llegado de Francke», carta de D. Alonso, 20.3.1953); tan lejos parecía ese acuerdo que el filólogo madrileño se hace eco del rumor - que se resiste a creer- ${ }^{38}$ de que la editorial helvética había firmado un convenio con el CSIC para editar el $D C E C$ :

Yo soy miembro del Consejo [Superior de Investigaciones Científicas] (aunque después de los insultos de [Joaquín de] Entrambasaguas a [Ramón Menéndez] Pidal —insultos groseros que han provocado la indignación de toda persona honrada - no sé si seguiré siendo miembro: desde luego no lo seré si el Consejo no da cumplida satisfacción a Pidal). ${ }^{39}$ Como miembro del Consejo yo, claro está, no tengo nada que oponer a que este lo haga. Pero sí me resultaría muy extraño que después del largo contacto de Francke con Gredos, el editor suizo se cambiara de repente de casaca (carta de D. Alonso, 20.3.1953).

${ }^{38}$ «Repito que no lo creo. Le ruego que omita mi nombre si menciona usted este rumor» (carta de D. Alonso, 20.3.1953).

${ }^{39}$ Con respecto a la provocación que supuso la publicación por Entrambasaguas de un infeliz cuento de carácter satírico contra don Ramón, vid. Pérez Pascual (1998: 318-327) y Catalán (2001, I: 323-324 y láminas lv-lviiii). 
El acuerdo entre ambas empresas cristalizó finalmente a las pocas semanas («he firmado ya el contrato con Francke y Gredos, y empezamos a componer», carta a Menéndez Pidal, 19.6.1953, Coromines 2006: 300). Esta solución permitió disponer en no mucho tiempo de la obra impresa, gracias a que la editorial española supo entender la importancia de este libro, componiendo un texto impecable, en el que ningún aspecto se descuidó (la tipografía, el papel...), como podemos apreciar en su intercambio epistolar con Dámaso Alonso:

Le creo ya en los EE. UU., y al mismo tiempo que le doy la bienvenida acompaño copia de mi carta a [Valentín García] Yebra, pues lo del papel es realmente de importancia suma, y aquí he oído ya muchas críticas por la imperfección de los tipos en la muestra que me enviaron el año pasado (carta a D. Alonso, 26.1.1954).

¿Sigue habiendo tipos machacados? Espero que no. Opino como usted que lo del papel es importante y yo estoy muy fastidiado por papeles últimamente empleados en la [Biblioteca] Románica [Hispánica], y les he amenazado con irme. Yo espero que con su libro de usted hagan un esfuerzo especial y considero indispensable que le envíen muestras de pliegos en el papel definitivo (carta de D. Alonso, 4.2.1954).

Una vez diseñada definitivamente la página («he aceptado ya en principio la impresión con linotipia en la imprenta de Gredos, pero quedan todavía algunos detalles tipográficos, que espero se resuelvan de un momento al otro») ${ }^{40}$ confiaba Coromines en «empezar a corregir pruebas sin más tardanza» (carta a Menéndez Pidal, 19.6.1953, Coromines 2006: 299-300); sin embargo, el proceso se alargará bastante más de lo que habría deseado, lo que se traduce en numerosas quejas que se deslizan en su epistolario:

Por ahora sólo he recibido de Gredos unas 70 galeradas del diccionario. Parece que les cuesta poner esto en marcha. Claro que yo les devuelvo las pruebas corregidas en seguida y por avión (carta a Menéndez Pidal, 17.10.1953, Coromines 2006: 312).

Por desgracia la composición del diccionario adelanta con una lentitud desesperante: después de 3 meses estamos todavía en $a j$ - de las galeradas. Si tiene usted que hablar con los de Gredos o con D. Alonso por otros asuntos, no estaría de más que les exhortara a un esfuerzo más rápido. Claro que yo estoy escribiéndoles carta tras carta (carta a Menéndez Pidal, 6.11.1953, Coromines 2006: 315-316).

Ni siquiera su permanencia en España por una larga temporada ${ }^{41}$ parece contribuir a acelerar el proceso, por lo que se queja a Dámaso Alonso:

Imaginaba que en llegando aquí aumentaría el ritmo del envío de pruebas del diccionario, en lo cual ganaríamos la Editorial y yo, pues cuestan mucho menos los envíos de Madrid a Barcelona, que de Madrid a Chicago. En realidad los envíos, por lo menos los de composición nueva, se han

\footnotetext{
${ }^{40}$ En misivas anteriores han comentado Coromines y Menéndez Pidal la realización de diversas pruebas en las imprentas: «Estamos haciendo con Gredos un ensayo de impresión de un trozo del diccionario para ver si puede componerse con linotipia (en lo que se empeñan ellos) o si hay que recurrir a la monotipia» (carta a Menéndez Pidal, 12.5.1953, Coromines 2006: 293); «iBien aferrados están en Gredos a la linotipia! Pero en fin, se esmeran en la corrección del Diccionario de usted» (carta a Coromines, 16.5.1953, Coromines 2006: 295).

${ }^{41}$ «Estoy a punto de salir para España, donde voy a pasar el trimestre de primavera [...]. Ya he avisado a [Valentín García] Yebra que en adelante me manden las pruebas a Barcelona» (carta a D. Alonso, 4.3.1954).
} 
interrumpido casi del todo desde mi llegada aquí. Y la dificultad del papel no lo explica todo pues esta se halla resuelta — creo- ya desde hace cerca de tres semanas (carta a D. Alonso, 11.5.1954).

Dámaso Alonso trata de tranquilizarlo ( «Veo que va usted con fatiga en lo del Diccionario: tengo entendido que a ellos el cambio de papel les ha perturbado bastante», carta de D. Alonso, 18.5.1954), pero sin conseguirlo, pues, aunque ya trabaje en la corrección del segundo volumen («ya tenemos toda la $\mathrm{CH}$ y más de la mitad de la D»), el lexicógrafo catalán se seguirá quejando de que «la imprenta trabaja mucho más despacio de lo que yo desearía» (carta a Menéndez Pidal, 9.11.1954, Coromines 2006: 317).

\section{OTRAS PERTURBACIONES}

No son los retrasos en la corrección de pruebas su única preocupación, pues Coromines se siente muy molesto al conocer la inmediata aparición del Diccionario etimológico español e hispánico (en adelante DEEH) de Vicente García de Diego: «Me escribe [Herbert L.] Baird que el Sr. García de Diego le ha hablado de un diccionario etimológico suyo, un manual breve de unas 900 páginas, que tiene preparado para publicar este año» (carta a D. Alonso, 26.1.1954). Desde el primer momento el filólogo catalán se manifiesta en tono despectivo sobre la obra de su colega:

Científicamente no me preocupa en absoluto; la obra de García de Diego está superada en etimología (en otros aspectos quizá nunca fue nada), y no porque pertenezca a una generación pasada, sino porque ya en su generación su obra fue siempre mediocre, aunque personalmente su edad y demás condiciones y circunstancias le hagan muy respetable. Tampoco un libro así puede hacer concurrencia apreciable a un diccionario extenso; además de la diferencia enorme de calidad y de orientación correcta, está ya la de amplitud de información (carta a D. Alonso, 26.1.1954).

Ciertamente Joan Coromines se muestra muy vehemente en sus juicios acerca de García de Diego; hay en su correspondencia significativos silencios sobre determinados filólogos españoles de su generación, así como amistosas alusiones sobre otros, pero no faltan tampoco comentarios ácidos sobre ciertos colegas, acerca de los cuales no se recata tampoco en opinar en letra impresa. En todo caso, no conviene ver en estas manifestaciones un juicio puntual mediatizado por el enfado ante la publicación de un volumen que va a competir con el $D C E C$, pues en otros intercambios epistolares ya se había manifestado muy crítico hacia este lexicógrafo, en quien ve un reflejo distorsionado de algunas de las tesis pidalinas con las que no está en absoluto de acuerdo:

Sobre la publicació del diccionari a Madrid m'agradaria de tenir el parer de vostè, relatiu al punt següent. El meu llibre pot afectar seriosament el prestigi científic d'alguns erudits madrilenys, sobretot el Sr. [Vicente] García de Diego: la seva obra era de palla i se n'ha anat quasi tota per terra. En el llibre evito tot personalisme però dono sempre el nom dels autors, i es notarà que en el que la seva obra tenia de personal (i no eco de [Wilhelm] Meyer Lübke o [Ramón] Menéndez Pidal) ha restat tota destruïda. Tampoc no m'abstinc de contradir Menéndez Pidal; aquest cas és del tot diferent: la seva obra és sólida, i en la major part dels casos he pogut confirmar la seva opinió; àdhuc moltes vegades en que l'havien rebutjada gent de gran autoritat; però en d'altres ocasions, que s'ha errat, ho demostro així, i val a dir que això passa moltes vegades, i algunes 
d'elles són idees predilectes de Menéndez Pidal. ${ }^{42}$ Els savis castellans tenen forta repugnància a admetre manlleus en mots importants del seu idioma, i per això han bastit aquesta teoria del caràcter fluctuant de les lleis fonetiques, teoria duta a un extrem absurd per García de Diego; força més moderada i defensada més habilment per Menéndez Pidal. Aquest no és el moment d'exposar les meves idees sobre la qüestió, que és complicada, car jo no sóc pas un neo-gramàtic; però en la doctrina de Menéndez Pidal encara resten molts casos de fluctuació completament arbitraria, que jo he de rebutjar. En el meu diccionari he de reconeixer que el lèxic castellà és un mosaic de manlleus, francesos, occitans, italians, portuguesos, i que en especial hi ha una quantitat de catalanismes incomparablement més gran del que es creia (carta a Sanchis Guarner, 19.12.1950, Coromines 2006b: 56-58).

Con todo, no podemos obviar que, además, Coromines es consciente de los daños comerciales que la publicación del $D E E H$ le puede acarrear:

a pesar de todo, en especial en cuanto a mi proyectado diccionario breve, ${ }^{43}$ un libro de [Vicente] García de Diego podría traerle algún perjuicio, y aun acaso mucho. No sólo porque el número de los tontos o semitontos es infinito, sino aún más porque son tan pocos en filología española los que están verdaderamente al día en lo que concierne a valores (parece mentira cuántos han tomado en serio, por ejemplo, la detestable Dialectología de García de Diego) ${ }^{44}$ (carta a D. Alonso, 26.1.1954).

Todavía muchos años después mostrará su enfado ante lo que juzgaba un comportamiento torticero por parte de su colega:

El Sr. García de Diego, cuando se enteró de que yo ya había concluido la redacción de mi diccionario y andaba buscando editor, se puso a escribir un diccionario etimológico, lo terminó a la diabla en un año y lo hizo imprimir precipitadamente, con objeto de madrugar a mis editores y quitarles la mejor tajada del beneficio a que aspiraban con su trabajo e inversiones; le ruego que lea usted, al principio de las adiciones a mi obra, tomo 4, un florilegio de los disparates, fruto de este proceder, en parte, con que ha puesto en ridículo la lingüística castellana, y sobre todo le ruego que se fije en su falta de probidad en la cita o invención de materiales, documentadas en los artículos venda, lar y otros de mis adiciones (carta a Navarro, 13.1.1959).

Por ello, Coromines se atreve a proponer a Dámaso Alonso que convenza a García de Diego de la conveniencia de retrasar la edición, igual que en el pasado habían renunciado a publicar sendos diccionarios etimológicos manuales Manuel de Montoliu y Martín de Riquer y

${ }^{42}$ Aunque considera que no va a sentirse ofendido por sus observaciones críticas: «En Menéndez Pidal va tenir en el seu poder gairebé un any l'original de tota la lletra $B$. Sé que va llegir-lo, i amb tot i que en aquesta lletra combato alguna de les seves idees predilectes (l'etimologia de bravo, per exemple), només em va fer algunes poques observacions sobre altres coses, molt poques i pertinents, que jo vaig tenir molt en compte» (carta a Sanchis Guarner, 19.12.1950, Coromines 2006b: 56-58). Desde luego, esas críticas a algunas de sus ideas más queridas no pasaron desapercibidas al patriarca de la filología española y años después le escribirá «sospecho que lo que yo diga me lo contradecirá usted quizá con menos vehemencia que en su gran Diccionario etimológico y quien sabe si no se convencerá usted algo de mis puntos de vista» (carta de Menéndez Pidal, 27.6.1959, Coromines 2006: 358).

${ }^{43}$ Coromines (1961); vid. infra apartado 6: 119-120.

${ }^{44}$ Ya años atrás había hecho llegar a Menéndez Pidal sus juicios negativos acerca de este manual de dialectología (carta a Menéndez Pidal, 10.9.1950, Coromines 2006: 235). 
Joan Petit; y si el volumen de Riquer y Petit estaba menos adelantado, Montoliu había llegado a entregar el suyo a un editor de Buenos Aires y había sido Amado Alonso, según insinúa Coromines, quien «paró el golpe» (carta a D. Alonso, 26.1.1954) y le tranquilizó:

Vi muestras del Diccionario etimológico de Montoliu. No le estorba al de usted absolutamente nada. Es para curiosos profanos (carta de A. Alonso, 31.3.1943).

\section{Y sugiere Coromines a Dámaso Alonso que}

Quizá se podría convencer al Sr. de Diego de que hiciera lo mismo, tomándole por el lado de la conveniencia científica: posibilidad de corregir — si publica el suyo más tarde - los que él crea «errores» míos (no me refiero tanto a los reales, que desde luego hay, porque dudo mucho de que él sea capaz de verlos), de rellenar mis lagunas, de «decidir» en los muchos casos que creí prudente dejar indecisos (de nuevo no le creo apto para tanto, pero es lícito decírselo), de agregar datos nuevos (fácil le será hacerlo teniendo acceso a los ficheros del Centro y de la Academia) y - sobre todo, claro está - aprovecharse de los míos y de mis ideas. Nada de esto me preocupa, todo lo contrario, pero tomando el asunto desde ese punto de vista quizá se le pueda convencer de que aplace, y así se evite la competencia comercial (carta a D. Alonso, 26.1.1954).

Sin embargo, Dámaso Alonso no tarda en desengañarlo:

En el asunto Diccionario de García de Diego no podemos hacer nada. Hace pocos días salí con él de la Academia y me dijo que «estaba casi impreso ya». Él ha procedido con cautela: no me ha dicho nada de que se estuviera imprimiendo (aunque sí sabía que lo tenía redactado), y ahora, de repente, me dice que ya está tirándose. Él ha hecho, precisamente, todo lo posible para que el suyo fuera por delante (carta de D. Alonso, 4.2.1954).

No obstante, intenta tranquilizar al filólogo catalán, pues considera que ese diccionario «no perjudicará nada al grande de usted, y poco al pequeño. Sí, claro está, que alguna parte del público comprará lo primero que le ofrezcan (y que muchos filólogos son imbéciles), pero otra parte (la mejor) comprará y propagará el de usted»; incluso parece encontrar ciertas ventajas comerciales en que el $D E E H$ se publique antes, pues ello «nos permitirá ver la reacción del público». Todavía informa a Coromines, con ironía, de que García de Diego le ha hablado de que

su diccionario está dividido en dos partes: si no recuerdo mal, una tiene un orden alfabético seguido; y la otra agrupa las palabras en torno a una raíz [...]. García de Diego parecía muy satisfecho de esta invención que no sé de dónde habrá mangado, pues es gran especialista en eso (carta de D. Alonso, 4.2.1954).

\section{El tRABAJO FILOLÓGiCO PROSIGUE}

Más allá de estos sinsabores, Coromines ya está planeando el paso siguiente y, mientras trabaja en la corrección de galeradas, prepara un nuevo producto lexicográfico, el Breve diccionario etimológico de la lengua castellana (en adelante BDEC). Y es que desde el momento mismo en que había empezado a diseñar el $D C E C$ había pensado en satisfacer no solo los requerimientos de un reducido número de filólogos y lingüistas, sino en ofrecer también una versión adaptada para un público más general: 
Para no cansar al profano culto con discusiones que forzosamente serán complicadas todavía vacilo entre dos procedimientos: a) un resumen en letra de cuerpo mayor al principio del artículo sin discusiones ni bibliografía, que quedarían para el resto del artículo, compuesto en un cuerpo más pequeño; b) dos diccionarios, uno de ellos, resumen del otro, dedicado al gran público, a los estudiantes, etc. (carta a Menéndez Pidal, 16.12.1943, Coromines 2006: 131).

al principio de todo, y antes del signo $\$$, van las conclusiones o parte destinada al público, redactadas con espíritu conservador y autocrítico (carta a Castro, 9.3.1947).

Como puede comprobarse, en el DCEC figuraba efectivamente al frente de cada entrada un breve resumen que podía dar cumplida satisfacción al lector no especializado; sin embargo, resultaba evidente que un diccionario reducido, publicado en un único volumen, podía llegar a un mercado potencialmente mucho mayor. Por ello, coincidiendo con la aparición del primer volumen del $D C E C$, Coromines se animó a remitir muestras del $B D E C$ a Dámaso Alonso («¿Recibió usted las muestras que le mandé a Madrid de mi diccionario abreviado?», carta a D. Alonso, 26.1.1954) y este obtuvo una primera impresión favorable, aunque no pudiese apenas examinarlas («Recibí las muestras del Diccionario abreviado: me parecieron bien. De todos modos, no tuve tiempo (he pasado unos meses malísimos con desgracias y disgustos variados) para verlas con toda calma. No sé si atreverme a pedirle que me enviara otras ahora», carta de D. Alonso, 4.2.1954). Coromines se las mandó nuevamente; en esta ocasión Dámaso reside en Massachussets unos meses y puede contestarle al punto y ofrecerle sus opiniones:

Gracias por haberme vuelto a enviar muestras. Me parece muy bien la desagrupación de voces. No veo claro el criterio con que en algunas ocasiones se mantiene la agrupación (una serie de palabras, por ejemplo, se remiten a estoma).

También me pregunto si no sería conveniente (dado el carácter popular o semipopular del libro) el consignar todos los sentidos principales de las voces. Me parece que [Oscar] Bloch y [Walter von] Wartburg lo hacen así [en el Dictionnaire étymologique de la langue française] (Bueno: no estoy seguro). El sentido mismo sirve para aclararle al lector la etimología; y cuando no la aclara, hay que dar al que lee una explicación del cambio semántico (como usted hace siempre).

Supongo que usted tiene todo esto pensado y repensado con sus pros y contras, que el que llega de fuera no ve (carta de D. Alonso, 16.2.1954).

Más allá de lo puramente científico, Dámaso Alonso es también consciente del potencial comercial del $B D E C$, ya que «El libro va a estar muy bien, y será un gran éxito» (carta de D. Alonso, 16.2.1954).

\section{LA APARICIÓN DEL DCEC}

Tras el complejo trabajo de composición y la complicada corrección de pruebas, a finales de 1954 aparece el primer tomo del diccionario. Conmueve comprobar cómo Menéndez Pidal, que había seguido tan de cerca la gestación del $D C E C$, se muestra realmente sorprendido por lo conseguido, al recibir el primer volumen, ${ }^{45}$ tanto como para decir que esta obra origi-

${ }^{45}$ No sin algún retraso, pues Coromines calculaba que le llegaría a principios del mes de noviembre («Más o menos al mismo tiempo que esta carta espero reciba usted el primer tomo del diccionario. Aguardo con emoción la impresión que le cause» (carta a Menéndez Pidal, 9.11.1954, Coromines 2006: 317), pero no fue así («Sé que ya se 
nará que no «la etimología, [sino] la historia entera del idioma tomará un rumbo más seguro y de horizontes más abiertos»; y concluye mostrándose convencido de que este libro hará época en la lingüística española (carta de Menéndez Pidal, 30.1.1955, Coromines 2006: 324-325).

Don Ramón muestra su interés porque «la obra se complete pronto: «[Valentín García] Yebra me dice que el cuarto tomo podrá aparecer para la primavera del 56, y eso será muy satisfactorio, porque el diccionario este será de consulta continua» (carta de Menéndez Pidal, 30.1.1955, Coromines 2006: 324). Con todo, no irá tan rápido el proceso como lo desean Coromines y su maestro: ${ }^{46}$ a fines del año 1955 ya había salido el segundo volumen, ${ }^{47}$ pero las correcciones de pruebas del tercero se prolongan hasta finales de 1956 y solo en octubre de 1957 se imprime por fin el cuarto tomo, en el que, aparte de los índices, figuraban unas importantes adiciones en que se intentaba incluir la investigación desarrollada en los últimos diez años en el terreno etimológico. ${ }^{48}$

Igual entusiasmo que Menéndez Pidal ante la publicación muestra Dámaso Alonso:

Estoy ahora corrigiendo pruebas de mi librito sobre el gallego-asturiano [...] y uso sin cesar su Diccionario de usted. ¡Portentoso!

Verdaderamente se siente uno muy avergonzado y se pregunta uno si merece la pena mover estas chinitas diminutas; la cantidad de trabajo y talento que hay en su libro es portentosa. El pobre [Yakov] Malkiel que tanto se afana con una inteligencia como la de un topo, supongo que debe estar desolado. Mi enhorabuena más entusiasta (carta de D. Alonso, 16.1.1956).

Tampoco se muestra parco en elogios uno de los filólogos por quienes Coromines sentía mayor admiración y cariño, Tomás Navarro Tomás:

Hasta ahora no había recibido su Diccionario..$^{49}$ Me llegan juntos los volúmenes I y II. ¡Qué obra tan enorme! Asombra pensar que pueda ser resultado del esfuerzo de un solo hombre. No es sólo

ha publicado el primer tomo del Diccionario, pero aún no lo he recibido» (carta a Coromines, 23.11.1954, Coromines, 2006: 320). «Hasta ahora no he visto más que un ejemplar del primer tomo de mi diccionario, recibido por avión. El primero que me entreguen mañana en Barcelona será para enviárselo a usted dedicado», aunque debe añadir en una postdata que «Al llegar a Barcelona veo que todavía no se han recibido ejemplares del diccionario. Reclamo y el primero que reciba será el que envíe a usted» (carta a Menéndez Pidal, 25.12.1954, Coromines 2006: 322-323).

${ }^{46}$ «Ja tinc corregides les proves fins a la fi de $H$; crec, doncs, que el $2 .{ }^{\mathrm{n}}$ volum sortirà abans de l'estiu, i el 3.r i el 4.t dins cosa d'un any» (carta a Sanchis Guarner, 14.3.1955, Coromines 2006b: 111).

${ }^{47}$ «¿Ha recibido usted ya el segundo tomo del diccionario? Supongo que se lo habrán mandado ya los de Gredos. Estoy ahora corrigiendo pruebas de la P. Ya casi empiezo a ver el fin de este otro esfuerzo» (carta a Menéndez Pidal, 1.11.1955, Coromines 2006: 327).

${ }^{48}$ «Espero que haya recibido usted ya el cuarto tomo de mi diccionario y que haya merecido su aprobación. El esfuerzo que me ha costado dotar el libro de índices completos, útiles y bien hechos ha sido grande, y aún más el de escribir las adiciones, donde he tratado de incluir la investigación de los 10 últimos y años y una infinidad de datos suplementarios y muy concentrados» (carta a Menéndez Pidal, 24.10.1957, Coromines 2006: 330). También le escribe a Nicolau d'Olwer que «la impressió del diccionari més absorbent que mai aquest any, pels índex alfabètics i temàtics i un llarg i densíssim suplement que hi he hagut d'afegir» (carta a Nicolau d'Olwer, 21.2.1957, Coromines 2008: 184).

${ }^{49}$ Casi un año antes le había indicado que «No he visto aún el primer tomo de su diccionario. Parece que la biblioteca de la Universidad tiene ya hecho el encargo, pero aun no lo ha recibido. Agradezco de antemano el anuncio de envío que usted me hace» (carta de Navarro, 21.7.1955). 
el acopio de tan inmensos materiales lo que produce impresión. Lo que más admira es el esfuerzo de selección, crítica y comentario con que usted los ha elaborado.

$\mathrm{Su}$ Diccionario es un acontecimiento en la filología española. Se siente uno orgulloso de ver en nuestra lengua una publicación semejante. Reciba mi entusiasta enhorabuena. Como obra indispensable en las bibliotecas se venderá lo necesario para que los demás volúmenes tengan asegurada la publicación (carta de Navarro, 26.5.1956).

Mucho más contenido y sobrio en la expresión, pero igualmente satisfecho, se muestra Rafael Lapesa al felicitar a Coromines «por ese espléndido diccionario, asombroso ejemplo de inteligencia y capacidad de trabajo» (carta de Lapesa, 15.1.1956).

$\mathrm{Y}$, sin embargo, a pesar de todos estos juicios tan laudatorios por parte de algunas de las máximas figuras de la Filología española, algo empaña la satisfacción de Coromines: y es que las felicitaciones y enhorabuenas que recibe epistolarmente no tengan su traducción impresa en reseñas. ${ }^{50}$

Acaba de este modo el largo viaje del $D C E C$, aunque Coromines no da por cerrada su labor etimológica sobre el castellano y, como indica más adelante a su maestro en otra carta, ya el $B D E C$, una joya en opinión de Américo Castro (carta de 25.11.1962), incorporará no pocas informaciones:

Dentro de poco saldrá mi Breve Diccionario Etimológico Castellano en un tomo, donde doy muchísimas fechaciones más antiguas que en el $D C E C$ y reviso algunas etimologías de este (carta a Menéndez Pidal, 13.4.1959, Coromines 2006: 344).

Este hecho será reconocido por sus usuarios, pues, como le escribirá Julio Casares, el $B D E C$ «no solo completa el magnífico Diccionario Crítico sino que pone al día muchos de sus artículos con datos nuevos que revelan una intensa y perseverante labor de investigación» (carta de Casares, 2.10.1963), y, además, ofrece el valor añadido de su portabilidad, como le sugiere Rafael Lapesa («utilísimo vademécum que consulto a cada paso y del que no me desprenderé en mis desplazamientos», carta de Lapesa, 18.10.1963). ${ }^{51}$

Mas lo cierto es que la publicación de tan monumental obra no le sirvió para obtener aquello que deseaba, el tan deseado acomodo en la universidad española: ni el trabajo tenaz de Coromines ni las sinceras gestiones en su favor de Ramón Menéndez Pidal o Dámaso Alonso consiguieron encontrar un hueco para el exiliado, ansioso por finalizar su involuntario alejamiento de la patria. Todo ello le causó el lógico desánimo, que no empañó, sin embargo, su habitual lucidez:

Regresé de España a primeros de octubre. No puedo decir que tuviera allá desengaños, pues sucedió más o menos lo que esperaba, ni puedo decir tampoco que hubiera razones para volver

${ }^{50}$ En el artículo en preparación «La recepción del DCEC de Joan Coromines» examino sus infructuosos esfuerzos en conseguir ser reseñado por algunos de los más destacados filólogos y, al tiempo, la cicatería de algunas de las recensiones publicadas.

${ }^{51}$ Todavía afrontará algunos años después una segunda edición, notablemente aumentada, del $D C E C$, realizada con la colaboración de José Antonio Pascual, el Diccionario crítico etimológico castellano e hispánico (DCECH), publicado entre 1980 y 1991. 
contento, pues aun los amigos se mostraron más fríos o indecisos de lo que hubiera podido esperar. Se me prodigaron palabras, pero es evidente que nadie apreció todo el esfuerzo que me ha costado escribir el diccionario, la extensión del sacrificio que me ha costado (carta a Navarro, 5.12.1952).

Dos décadas de titánico esfuerzo no obtuvieron, pues, la recompensa anhelada y, como escribe lapidariamente a su maestro, la ilusión «de que este libro pudiera volver a abrirme las puertas de la Universidad patria pasó hace tiempo» (carta a Menéndez Pidal, 24.10.1957, Coromines 2006: 331). Pero, como le escribe también desde el exilio Tomás Navarro

Nadie podrá impedir que multitud de personas dentro y fuera de nuestra tierra le conozcan a usted y le consulten en los volúmenes de su gran Diccionario etimológico. Aunque no se le tributara a usted ningún homenaje siempre quedará patente el servicio que usted ha prestado con su admirable obra a la filología española (carta de Navarro, 27.1.1958).

\section{REFERENCIAS BIBLIOGRÁFICAS}

Alcover, Antoni Maria y Francesc de Borja Moll (1930-1962): Diccionari català, valencià, balear, Palma de Mallorca, Moll [DCVB].

BAdia i MARgarit, ANTONi Ma , ed. (2006): Homenatge de l'IEC a Joan Coromines, en el centenari de la seva naixença. Cicle de conferències, Barcelona, Institut d'Estudis Catalans.

Blecua, José Manuel y Gloria Clavería (1999): «La lexicografía castellana, antes y después de Coromines», en Joan Solà, ed., L'obra de Joan Coromines, Sabadell, Fundació Caixa de Sabadell, pp. 29-43.

CAtalán, Diego (2001): El Archivo del Romancero, Madrid, Fundación Ramón Menéndez Pidal.

Coromines, Joan (1954-1957): Diccionario crítico etimológico de la lengua castellana, Madrid-Berna, Gredos-Francke [DCEC].

Coromines, Joan (1961): Breve diccionario etimológico de la lengua castellana, Madrid, Gredos $[B D E C]$.

Coromines, Joan (2000): Epistolari Joan Coromines-Francesc de B. Moll, edición de Josep Ferrer y Joan Pujadas, Barcelona, Fundació Pere Coromines.

Coromines, Joan (2001): Epistolari Joan Coromines \& Josep Pla, edición de Josep Ferrer y Joan Pujadas, Barcelona, Fundació Pere Coromines.

Coromines, Joan (2003): Epistolari de Joan Coromines amb exiliats catalans d'America: Hipòlit Nadal i Mallol i Avel-lí Artís i Balaguer, ed. de Josep Ferrer y Joan Pujadas, Barcelona, Fundació Pere Coromines.

Coromines, Joan (2006): Epistolario Joan Coromines \& Ramón Menéndez Pidal, edición de José Antonio Pascual y José Ignacio Pérez Pascual, Barcelona, Fundació Pere Coromines.

Coromines, Joan (2006b): Epistolari Joan Coromines \& Manuel Sanchis Guarner, edición de Josep Ferrer y Joan Pujadas, Barcelona, Fundació Pere Coromines. 
Coromines, Joan (2008): Epistolari Joan Coromines \& Lluís Nicolau d'Olwer, edición de Josep Ferrer y Joan Pujadas, Barcelona, Fundació Pere Coromines.

Coromines, Joan (2008b): Epistolari Joan Coromines \& Francesc Cambó. La gènesi de la «Miscel·lània Fabra», edición de Josep Ferrer y Joan Pujadas, Barcelona, Fundació Pere Coromines.

Coromines, Joan (2009): Epistolari Joan Coromines \& Josep M. Batista i Roca, Joan Triadú, Albert Manent i Max Cahner, edición de Josep Ferrer y Joan Pujadas, Barcelona, Fundació Pere Coromines.

Coromines, Joan y José Antonio Pascual (1980-1991): Diccionario crítico etimológico castellano e hispánico, Madrid, Gredos [DCECH].

Ferrer i Costa, Josep (2005): «L'Epistolari Joan Coromines o el joc de les paradoxes», Escola catalana, 425, pp. 15-16.

García De Diego, Vicente (1954): Diccionario etimológico español e hispánico, Madrid, SAETA [DEEH; ${ }^{\mathrm{a}}{ }^{\mathrm{e}}$ ed. aumentada con materiales inéditos a cargo de C. García de Diego, Madrid, Espasa-Calpe, 1985].

Pascual, José Antonio y José Ignacio Pérez Pascual (2003): «La pasión por la etimología. Crónica del Diccionario crítico etimológico de la lengua castellana de Joan Corominas», en Lexicografía y lexicología en Europa y América. Homenaje a Günther Haensch, Madrid, Gredos, pp. 509-535.

Pascual, José Antonio y José Ignacio Pérez PAscual (2006): «El Diccionario crítico etimológico de la lengua castellana de Joan Coromines: una aventura intelectual y vital», en Joan Coromines, Epistolario Joan Coromines \& Ramón Menéndez Pidal, edición de José Antonio Pascual y José Ignacio Pérez Pascual, Barcelona, Fundació Pere Coromines, pp. 9-63.

Pérez Pascual, José Ignacio (1998): Ramón Menéndez Pidal. Ciencia y pasión, Valladolid, Junta de Castilla y León.

Pérez Pascual, José Ignacio (1999): «Notas sobre la prehistoria del Atlas Lingüistico de la Península Ibérica», en Lengua y discurso. Estudios dedicados al profesor Vidal Lamíquiz, Madrid, Arco/Libros, pp. 751-760.

PéRez Pascual, José Ignacio (2007): «Joan Coromines y el Diccionario crítico etimológico castellano», Zeitschrift für Katalanistik, 20, pp. 83-100.

PÉRez Pascual, José Ignacio (2007b): «Pidal y los estudios dialectales», en José Ramón Morala, ed., Ramón Menéndez Pidal y el dialecto leonés (1906-2006), s. 1., Instituto Castellano y Leonés de la Lengua, pp. 47-80.

Pérez Pascual, José Ignacio (2007c): «Los estudios de dialectología en el Centro de estudios Históricos. La realización del ALPI», Moenia, 13, pp. 401-430.

Pérez Pascual, José Ignacio (2008): «Los estudios de dialectología en el Centro de estudios Históricos. El difícil camino del Atlas lingüistico de la Península Ibérica», Boletín de la Fundación Federico García Lorca, 44, pp. 71-93.

PORTO DAPENA, José-Álvaro (2000): «Diccionarios históricos y etimológicos del español», en Ignacio Ahumada, ed., Cinco siglos de lexicografía española, Jaén, Universidad de Jaén, 2000, pp. 103125.

SALVAdOR, Gregorio (1985): Semántica y lexicología del español, Madrid, Paraninfo.

SolÀ, Joan, ed. (1999): L'obra de Joan Coromines, Sabadell, Fundació Caixa de Sabadell. 


\section{ANEXO \\ I \\ CARTA de JoAn Coromines A AmÉrico Castro (Chicago, 9.3.1947)}

Mi querido Maestro:

Mucho he tardado en escribir el artículo baratar, y por ello en contestar a su amabilísima carta. Espero que sea usted indulgente con mis razones. Cuando llegué a baratar en el orden alfabético (ahora ya estoy en bocezar) lo salté, pues acababa de recibir su carta aquel mismo día y como nunca había pensado detenidamente en el problema quise dejarlo madurar en mi cerebro. Por otra parte me esfuerzo en hacer cada día una tarea mínima, equivalente a una página o dos columnas, o cuatro, del diccionario vulgar de la Academia, pues si no lo hiciera así y me detuviera mucho en los problemas individuales e interesantísimos de las varias palabras difíciles, mi diccionario sería tal vez mejor, pero se eternizaría y no llegaría a ser nada, o nunca. Esta obra se ha apoderado tan terriblemente de mí, que el día en que no llego a hacer la tarea mínima, por la noche no puedo dormir. Y es el caso que últimamente he tropezado con una larga racha de palabras difíciles, durante varias semanas, que me han puesto en figurillas para hacer cada día la tarea mínima. Por esto iba aplazando baratar, hasta anteayer que me quedé trabajando hasta la madrugada y aquí se lo mando.

Esta es una cuestión de las más oscuras. En casos así he llegado a la conclusión de que lo único honesto frente al público no especializado es la fórmula fatídica: «origen desconocido».

Sin embargo, como mi obra se dirige también y aun más a los especializados, divido cada artículo en varias partes, separadas por signos convencionales (que en lo impreso se representarán de otro modo: una manecilla, impresión sangrada, etc.). Lo del «origen desconocido» entonces, no quiere decir que no se sepa nada, sino que no está lo bastante clarificado para poder pasar desde ahora a los manuales de enseñanza anterior a los seminarios. Entre ello cuento su etimología. Esta parte de discusión, documentación y bibliografía va precedida del signo (provisional) $\times$. Tras el signo va la fecha de la primera edición del vocablo, y aquí es más provisional todo, el signo y la fecha misma, pues nadie mejor que usted sabe lo atrasados que están esta clase de trabajos para el castellano, tan adelantados en francés, inglés y alemán (los hados han querido que el fichero del Centro de Estudios Históricos no haya de poder utilizarse en mi obra, y sobre todo cuando se terminen los dos tomos publicados del Diccionario Histórico de la Academia, el de Autoridades me servirá de muy poco; pero creo que es mejor esto que nada, y que así daremos un primer paso; claro que no me limito a los diccionarios de la Academia, sino que consulto los glosarios de autores y tengo a la mano Alonso de Palencia, Nebrija, Pedro de Alcalá, tendré Oudin, y además tengo una infinidad de fichas que he hecho estos años, de casos de aparición temprana de vocablos). Finalmente el signo $<$ precede a los derivados (en el orden alfabético habrá una referencia) y el signo $>$ precede a los compuestos. En fin, o mejor dicho, al principio de todo, y antes del signo \$, van las conclusiones o parte destinada al público, redactadas con espíritu muy conservador y autocrítico.

He reproducido el texto de su nota, sin más que algunos retoques ínfimos (agregando alguna fecha o repitiendo alguna palabra, con miras a los lectores, colocando al final la frase que usted ponía al principio a modo de conclusión anticipada y tratando de interpretar su sentido, todo lo cual era necesario para pasar del estilo epistolar al lexicográfico). Dígame usted 
si he acertado. Pongo su etimología en nota, para que no aparezca que me atribuyo lo que no es fruto de mi ingenio; en el texto sería más difícil recalcar que esto es de D. Américo Castro. Pero si a usted le parece mejor podría pasar al texto, o si no lo desea usted (sobre todo si va usted a publicarlo) se puede suprimir. Tenga usted la bondad de decirme con toda franqueza lo que desea.

Desde luego tengo que prohibirme intransigentemente toda investigación prolongada y monográfica de una palabra, mientras no haya concluido el diccionario. Este libro es de una urgencia primordial para todo el mundo. Por imperfecto que sea, él será el punto de partida. También desde el punto de vista personal tengo que prohibírmelo: estoy abusando de mis fuerzas, trabajando 10 o 12 horas diarias y ojalá que mi salud llegue bien, como hasta aquí, al final de mi obra.

Salen muchos resultados interesantes. Esta palabra bizarro que a modo de tópico repetido sin análisis desde Larramendi y Diez, se venía citando siempre como iberismo difundido por Italia y Francia, ni tiene que ver nada con el vasco, ni en España se halla antes de Ercilla, mientras que en Italia se usó sin interrupción desde Dante, y allí deriva de bizza 'rabieta', de donde 'furioso' (Dante), 'fogoso', y de aquí los sentidos castellanos y por otra parte 'raro, extravagante' (italiano, francés). Todavía Las Casas sabe que bizarro es palabra italiana y no castellana. Y las variadísimas acepciones clásicas españolas ('valiente', 'elegante', 'gallardo', 'cortés', etc.) muestran toda la vaguedad de una palabra a la moda recién traída de la elegante Italia del Renacimiento, y es visible para cualquiera que tenga un leve sentido estilístico el «engouement» que sienten por ella Cervantes, Lope, Alemán, Vélez de Guevara, etc. Como en tantas cosas se ha tenido por archi-español (¡el bizarro militar!) lo que es postizo e importación moderna. El sufijo -arro, -erro, -urro es también italiano (centro-italiano) y allí viene del substrato etrusco (Volaterra, Suburra, ramarro 'lagarto', tabarro, etc.). Tampoco garra tiene que ver con lo ibérico, pues viene de garfa (única forma medieval), con asimilación de la $h$ aspirada $(<\mathrm{F})$ a la $r$, como en márrega $<$ márfega, y está en relación con garfio. Por otra parte se revelan como creaciones hispánicas voces que se tenían por forasteras: baliza, mozarabismo lisboeta derivado de palo, y extendido a toda Europa desde la capital portuguesa, cuyo puerto fluvial siempre amenazado por los aluviones del río requirió la invención de la baliza; bacalao y besugo extendidos a todas partes por los pescadores del Cantábrico; el holandés bakeljauw, que con su $l j$ y su - $a u$ huele a romance a la legua, tiene tan poco de originario como el vesurgius del Glosario de Toledo (por lo visto a un glosador se le ocurrió traer el besugo del Weser o Visurgis alemán, nada menos); batán, arabismo llevado a Francia, uno de tantos términos hidráulicos propagados por los árabes, y no un francés battent que no existe; batayola 'parte del buque donde se combatía' y de aquí batahola, tabahola, catalán desde el Consulado de Mar, y extendido desde allí, con la pronunciación dialectal de $l l>y$ o cero. Gaita, lejos de venir del provenzal o del árabe, es reliquia gótica (gótico gaits 'cabra'= inglés goat, alemán geiss; la gaita se llama cabreta en provenzal, y los textos gallegos aluden siempre a la piel de cabra con que se hace la gaita), y desde España se extendió hasta el Lago Chad y a Constantinopla y de allí llegó hasta el polaco. También creo haber hallado la etimología gótica de barragán 'mancebo luchador', emparentado con barón (*BARRICA, BARRIKANS, diminutivo hipocorístico formado como Egica, Ennica, Ennicus, de donde Iñigo, etc.).

Pero más útil aún que todo esto, creo que será la crítica serena e implacable de las etimologías que circulan en los diccionarios, el primer intento de fijar los jalones cronológicos y geográficos, y eliminar los ghost-words que tanto abundan en el diccionario académico (iy so- 
bre todo las ghost-meanings!), en fin las fundaciones filológicas de la empresa etimológica. Se viene repitiendo que barro es palabra prerromance que se extiende desde Portugal hasta Valonia e Istria, pero en realidad el italiano barro sólo significa 'búcaro' y es hispanismo recentísimo, el foco valón es reducidísimo y de forma muy diferente, el vocablo es ajeno del todo a los dialectos franceses, italianos y catalanes y en lengua de Oc sólo se halla en Gascuña y Oeste de Languedoc, de modo que tenemos un área típicamente ibera; además la acepción 'fango' es moderna, en lo antiguo sólo era 'arcilla' como en portugués. Algún hallazgo puede abrir puntos de vista nuevos sobre temas literarios e históricos, como el de gaita sobre la influencia lírica hispánica popular sobre la arábiga y no al revés; pero la misión del diccionario no es explotarlos, otros lo harán, o quizá en parte yo mismo, pero más tarde. Ahora la cuestión es que pueda terminar la obra. Al paso que llevo tengo para 3 años por lo menos. En adelante podré acelerar pues ya tengo completo un fichero fechador que he tenido que ir haciendo, y la masa enorme de mis papeletas (más de 200.000), ha quedado ordenada (hasta hace 15 días tenía que ir reuniendo yo mismo 11 grupos de fichas, ordenados por separado, a medida que adelantaba la redacción, y ahora ya puede hacerlo el único auxiliar con quien cuento); mas por otra parte también me veré obligado a reducir a lo normal mi horario que hasta aquí ha sido de 10 y 12 horas diarias, si no quiero caer enfermo. Llevo escritas 140 páginas como estas que ve usted. No hay necesidad de que me devuelva usted la copia, pues tengo otra, a no ser que quiera hacer en ella las correcciones que puedan hacer falta.

De nuevo perdone usted mi retraso y silencio. Y perdone que no le hable de otros asuntos: debo seguir escribiendo el libro. Siento de veras no haber podido averiguar dónde aparecieron las demás etimologías arábigas que según creo publicó usted. Aquí no hallo ninguna referencia en el catálogo de la biblioteca.

Le repito mi agradecimiento y quedo de usted muy atento y cordial servidor y discípulo.

II

CARTAS DE JoAn COROMINES CON RAFAel LAPESA Y Julio CASARES

Carta de JoAn Coromines a Rafael Lapesa (Chicago, 27.2.1948)

Mi querido amigo:

En cartas con D. Ramón hemos hablado de la posibilidad de que vaya yo a trabajar en el Instituto Cervantes, en fecha por ahora indefinida. Me sugiere él que me dirija a usted para que me oriente en un terreno que me es ahora tan desconocido como aquél.

Yo no sé nada del Instituto Cervantes, nombre que parece nuevo. No parece que tenga que ver con el antiguo Centro de Estudios Históricos, hoy Instituto Nebrija. ¿O vuelve D. Ramón a tener alguna autoridad en la vieja casa? El nombre sugiere más bien la dirección y estudio del idioma, y por lo tanto relación con la Academia de la Lengua, de la cual me han asegurado no hace mucho (y no sé con qué conocimiento del asunto) que D. Ramón vuelve a ser Director. Dígame usted, si lo sabe, si el Instituto Cervantes cuenta con una importante biblioteca propia (especialmente colecciones de escritores clásicos y medievales, colecciones de revistas romanísticas, las grandes fuentes lexicográficas latinas, italianas, arábigas, del francés y del provenzal antiguos, atlas lingüísticos, etc.), o si, estando situado cerca del edificio de la 
Academia de la Lengua o del Centro de Estudios Históricos, tienen sus colaboradores fácil acceso a las bibliotecas de estos centros.

Lo único que me dice D. Ramón es que es Presidente del Instituto Cervantes, y Casares Director efectivo. Supongo se trata de Julio Casares, el de Crítica Efímera, etc. Sé poco de este señor. Sus escritos me informan suficientemente de su preparación filológica, y por otra parte dan idea de una discreta inteligencia. El hecho de su íntima e ininterrumpida relación con la Academia desde el tiempo de la monarquía no da idea de un hombre a quien se haya colocado en su puesto por su celo político; pero este aspecto es el que realmente desconozco.

Acercándonos más a los problemas cotidianos, y para el caso de que las propuestas llegaran a concretarse, me habla ya D. Ramón de la posibilidad de vivir con mi mujer en la Residencia del Consejo Superior de Investigaciones Científicas, y de comer allí. Por la dirección veo que se trata de la antigua Residencia de Estudiantes dirigida entonces por el Sr. [Alberto] Jiménez Fraud, aunque no sé cuánto se habrá salvado de la tradición de aquella casa, fuera del edificio. Pero hay sobre todo las cuestiones materiales. Me acuerdo de que cuando yo vivía allí la comida era suficiente, pero más sobria que abundante. Y mi mujer me dice que lo general ahora en las pensiones españolas es que los huéspedes hayan de buscar afuera un suplemento de alimentación. ¿Puede usted decirme si esto se aplica a la actual Residencia, y en qué cantidad mensual aproximada evaluaría usted este suplemento?

También le ruego que me diga si cree usted que un hombre como yo, sin actuación política personal, pero de antecedentes familiares conocidos, y de convicciones liberales, debe contar con la exigencia de alguna declaración política y aun con otras molestias de este tipo.

Mi diccionario adelanta despacio, aunque ya estoy en CL-, y más podré ir adelantando cuando termine la terrible letra C. La idea de D. Ramón es que yo complete allí los datos que era imposible obtener en Chicago. No sé hasta qué punto podré entonces dedicarme del todo a esta tarea mía o habré de atender además a trabajos del Instituto Cervantes, trabajos de investigación o aun docentes. Es probable que D. Ramón no le dijera a usted cuáles eran sus planes a este respecto. Claro que en otro caso le agradecería a usted sus informes, ya que de todos modos me sería útil cualquier impresión suya acerca de este punto y otros que se le ocurran. Por lo demás esto y lo anterior puede haber cambiado mucho cuando venga el momento.

Por ciertas vaguedades en las cartas del Maestro se me ocurre conjeturar que él teme que alguien lea o someta sus cartas o las que él recibe a alguna especie de censura oficiosa, y que quizá prefiera que yo me dirija a él por conductos indirectos o reservados. ¿Tiene usted la impresión de que esta vaga impresión mía esté fundada?

Usted ve que todo esto es impreciso y distante. En mí hay algo del deseo de ir alimentando la imaginación en este ambiente desconsolador. Y de momento tengo que vivir aquí. Yo le agradeceré muy de veras que guarde sobre ello completa reserva, aun con los amigos.

Recibí y le estimé mucho su amable carta. He dejado a un lado lo de asenderear. Qué lástima que la nueva redacción, tan necesaria y preferible, del Diccionario Histórico no empiece por CI- (a reserva de publicar de nuevo A, B, CA y CE una vez terminada la obra). Lo más importante será, de todos modos, que se haga bien, por manos peritas como las de usted.

Perdone mi retraso en contestarle. Usted imaginará que escribiendo anualmente un millar de páginas del diccionario, sin abandonar la enseñanza a full-time, y a razón de tres cursos trimestrales por año, debo tener abandonada la correspondencia y aun trabajar día y noche.

¿Cómo lo pasa a usted en Princeton? Por la prensa veo que ahí se dan cuenta de que los profesores tienen que hallar casa y pagar más de una semana por comer y subsistir; aquí pare- 
ce que esperan que nos convirtamos en almas incorpóreas. Sentí muchísimo no verle en el Congreso de la Modern Language Association en Detroit.

Disculpándome por haberle distraído y con la esperanza de serle útil en algo, le manda un abrazo afectuoso su amigo y viejo compañero

\section{Carta de Rafael Lapesa a Joan Coromines (Princeton, 4.3.1948)}

Mi querido amigo:

Verá usted lo que sé del Instituto Cervantes, que es un brote más de los muchos que han nacido en el frondoso árbol luliano del Congreso [sic] de Investigaciones Científicas. La gestación comenzó, según parece, en marzo de 1947; pero la creación del Instituto se hizo en octubre (¿saldrá sietemesino?), aprovechando la coyuntura de la Asamblea Cervantina que se celebraba en Madrid entonces. Más que creación se trata de una partición, pues el nuevo órgano se ocupará de todo lo que antes tenía de Filología hispánica el Nebrija, cuyo campo se reduce ahora a la Filología clásica. Tal vez figuraran entre los motivos de la bipartición algunas incompatibilidades de caracteres.

La disposición que creó el Cervantes preceptuaba que la Presidencia quedase vinculada a la Dirección de la Academia Española y que, además, el Instituto tuviese un Director, que habría de ser también académico. Se hizo así pensando indudablemente en que [José $\mathrm{M}^{\mathrm{a}}$ ] Pemán seguiría dirigiendo la Academia y sería un presidente formulario del Cervantes; entonces también se pensó en Casares como Director efectivo. Al ser reelegido don Ramón Director de la Academia, ha recaído automáticamente en él la Presidencia del Instituto. Yo no sé decir a usted si está dispuesto o no a tener una intervención activa. Hasta noviembre su actitud respecto al Consejo [Superior] de Investigaciones era de apartamiento; no sé ahora. Tal vez Dámaso [Alonso], que ha estado en Madrid hasta febrero y se encuentra ahora en Yale, pueda dar a usted noticias más recientes y directas, como miembro importante del Instituto. Respecto a Casares, he estado en mucha relación con él desde marzo a diciembre, porque yo trabajaba como colaborador en un Seminario de Lexicografía creado en la Academia — creo que ya le escribí sobre ello - y él era su Director. Es persona enterada y con deseo de hacer bien las cosas. Se ha propuesto hacer un Diccionario Histórico decente y quiere rodearse de buenos colaboradores. Varias veces me habló de la necesidad de un Seminario u organismo análogo para el estudio de las etimologías. Yo le hice saber que usted tenía muy avanzada la elaboración de su Diccionario etimológico, y me preguntó muy interesado dónde estaba usted y si habría posibilidad de que volviera a España. Como materiales disponibles tendría usted las bibliotecas del Cervantes, correspondiente a parte de la del Centro de Estudios Históricos, la de la Academia y los ficheros lexicográficos de ambos sitios (400.000 papeletas buenas en el Cervantes, del proyectado Vocabulario medieval que no llegó a hacerse; 4 millones y medio de papeletas buenas y malas en la Academia).

La Residencia del Consejo de Investigaciones ocupa, efectivamente, el local de la antigua Residencia de Estudiantes. Ahora está destinada a los investigadores, sobre todo extranjeros, y puesta con mucho lujo. Yo he comido alguna vez y tengo la impresión de que la comida fue abundante, aunque tal vez no demasiado perfecta en el aspecto culinario; en general, creo que se come bastante bien.

La otra pregunta de usted, sobre posibles molestias políticas, es difícil de contestar para 
quien, como yo, sólo puede darle una impresión personal, sin fundamentos oficiosos. Creo que ahora las altas esferas de la España oficial desean el regreso de quienes están en el caso de usted. Es posible que tenga usted que hacer alguna declaración depuratoria en el consulado. En cuanto a manifestaciones utilizables en Madrid para propaganda, creo que con un poco de habilidad y cautela se pueden evitar. En cuanto a las vaguedades en la correspondencia, indudablemente se deben a los motivos que usted supone.

Mi impresión de Princeton es agradable: vida tranquila, mezcla ideal de ambiente universitario, comodidades ciudadanas y apartamiento campestre. En cuanto a las mejores económicas, soy profesor visitante y no sé si me alcanzarán.

Guardaré absoluta reserva sobre sus consultas. Solamente le pido que la tenga usted también respecto a mi contestación. Le abraza

P.S. Creo le interesará saber quiénes serán probablemente las figuras dirigentes de las secciones en el Instituto. Cuando salí de Madrid, a primero de enero se hablaba de Dámaso [Alonso], [Joaquín de] Entrambasaguas y [Rafael de] Balbín. Como lo digo, Dámaso está en Yale y permanecerá allí hasta junio.

\section{CARTA de JoAn Coromines a Julio Casares (Chicago, 20.1.1949)}

Muy respetado colega y distinguido amigo:

Hace unos pocos días recibí su atenta carta de 23 de noviembre, donde leo amables frases que no sé cómo agradecerle. Permítame usted, antes de contestar a sus palabras, manifestarle que tuve una honda satisfacción el año pasado al enterarme de que el Director del nuevo Instituto era el autor de Crítica efimera, Nuevo Concepto del Diccionario y tantos doctos trabajos. Recuerdo que ya hace muchos años leí un artículo de usted acerca del Diccionario vulgar de la Academia, y habiéndome parecido una de las críticas más inteligentes que se han escrito acerca de esta obra - y escrita desde dentro-, quise leer esos otros libros; desde entonces he permanecido, desde lejos y silenciosamente, en contacto con su obra. No hace muchos meses que el artículo de mi diccionario etimológico sobre cierne me dio ocasión de renovar aquel contacto, justamente (por un azar del orden alfabético) por los días en que me enteré de la creación del Instituto Cervantes. Pensé que había colaborado con usted en la palabra cierne, y que también me gustaría ser su «colaborador en cierne».

En efecto estoy convencido de mi deber patriótico de regresar a España. Con mis estudios, en Madrid, en Suiza y en otras universidades extranjeras, con mi actividad lexicológica ininterrumpida durante 25 años, y con mis años de residencia en la América española (que no fueron infructuosos en cuanto al estudio del castellano local, y por suerte pude llevarme la masa enorme de materiales coleccionados allí y descritos en los informes anuales que puede usted leer en mis Anales [de Lingüística] de Cuyo), creo haber adquirido un cúmulo de conocimientos que puede ser de considerable utilidad al Instituto y de la propia Academia.

Pero aquí tengo una posición, que además de ser muy buena, me ofrece una garantía absoluta de seguridad para el resto de mi vida. Y si yo puedo sacrificar a la patria esta seguridad de la vejez, no tengo derecho, en cuanto a los míos, a imponerles además sacrificios, que si ahora serían importantes, dentro de poco se pueden hacer intolerables. Por ello estoy decidido a no moverme sino en las condiciones que propuse a D. Ramón Menéndez Pidal.

Comprendo que un sueldo del Instituto sería compatible con una cátedra, como usted 
dice. Pero en mi caso hay motivo para temer que este camino me estuviera cerrado para siempre o para muchos años: ¿obtendré jamás la aprobación de ciertos organismos que gozan de decisivo influjo en la dirección actual de la enseñanza y que se oponen intransigentemente al que ha reivindicado un mínimo de libertad de conciencia? Lo dudo tanto que sólo podría tener en cuenta este factor si usted y D. Ramón, juntando el peso de su autoridad, me obtuvieran de antemano un nombramiento de este tipo; o, de no ser esto posible en mi ausencia, por lo menos la promesa firme (por parte de quien pueda garantirla) de que tal nombramiento se realizaría inmediatamente después de mi llegada a España. D. Ramón podría informarle de lo que puedo enseñar; me bastará recordar que aquí soy el profesor de filología francesa, provenzal y española, que en la Argentina fui catedrático titular de latín (además de filología romance) y que allí y en Barcelona enseñé literatura española y algunas veces ambas lenguas clásicas. En la facultad de Filosofía y Letras de Barcelona fui Auxiliar, por concurso, de Lengua y Literatura Españolas, durante ocho años desde 1930, y posteriormente se me nombró profesor agregado en la misma Facultad.

Crea usted que en verdad me complacería colaborar en su obra. En todo caso se lo aseguro que siempre tendré la mayor satisfacción si puedo servirle de algo.

Con verdaderos deseos de serle útil, queda de usted sincero y muy atento servidor, que estrecha su mano.

Carta de Julio Casares a Joan Coromines (Madrid, 28.2.1949)

Mi admirado colega y querido amigo:

Recibí oportunamente su atenta carta de 20 del pasado, a la que no he contestado antes porque tanto D. Ramón, con quien he estado al habla, como yo, deseábamos hacer ciertos tanteos preliminares antes de comunicarle nuestro parecer. El mío, expuesto con toda franqueza y lealtad con que tengo costumbre de expresarme, se reduce a decirle que cuando se tiene como usted «una posición que, además de ser muy buena, ofrece una garantía absoluta de seguridad para el resto de la vida», no es aconsejable un cambio de postura, si no hay para ello consideraciones de mucho peso, máxime si ese cambio supone imponer sacrificios importantes a los seres queridos. Las situaciones económicas con que hemos de contentarnos por acá no se puede decir que sean «muy buenas», y en cuanto a las garantías que usted muy prudentemente reclama, tampoco estaría en nuestras manos asegurarlas para lo futuro, aunque las obtuviéramos de momento. Renuncio, pues, a la satisfacción que me prometía tenerle aquí trabajando a nuestro lado, pero no renuncio a aprovechar el ofrecimiento de colaboración con que me honra, y espero que muy pronto lo habré de poner a contribución.

Si no tiene usted el volumen IV de mis Obras Completas, titulado Cosas del lenguaje, tendré mucho gusto en enviárselo.

Y sin más por hoy, queda de usted atento amigo y sincero admirador, que estrecha su mano. 


\section{ANEXO III \\ Carta de JoAn Coromines a DÁmaso Alonso (BARCElona, 14.8.1952)}

Mi querido amigo y distinguido colega:

Desde mi llegada me he acordado constantemente de mi promesa de enviarle tiradas aparte de mis trabajos. Si no lo he hecho es porque estas tiradas están en las cajas clavadas en que traje mis papeles de los EE.UU., y en mi situación provisional (sin casa permanente, etc.) todavía no he podido abrirlas. He encontrado, sin embargo, ejemplares de algunas en otras partes y se las remito por el mismo correo; las demás seguirán cuando abra las cajas.

Con el mayor interés y con honda emoción leí en Ínsula su artículo necrológico de Amado Alonso. Unos días antes había leído en sesión plenaria del Institut d'Estudis Catalans una necrológica mía bastante extensa, en que decía muchas cosas parecidas. Cuando se publique se le enviaré. Qué pena tan profunda para todos.

A fines o mediados de mayo escribí a don Ramón una carta en que decía lo siguiente. Refiriéndome a la conversación que tuvimos durante mi paso por Madrid sobre la decadencia actual de Francia, muy acosada e irreparable en materia de Filología Romance, le explicaba mi convicción de que este carácter irreparable y catastrófico se debe al acaparamiento ya antiguo de todos los valores franceses por parte de París: si ocurre la desgracia de que este centro único cae en manos de gente mediocre y celosa, que es lo que pasa allí, la desgracia no tiene remedio. Y se da el caso de que en la España actual, donde tanto se cacarea la oposición a Francia, se imita servilmente a los franceses en las cosas peores que hacen. A Madrid se quiere llevar a todos los valores españoles, y los demás centros de España se suprimen resuelta e implacablemente, o se les impone una fatal capitis deminutio. Lo cual ya es antiguo y no ha dejado de practicarse con fría tenacidad y constancia imperturbable desde el siglo XVIII. A pesar de todo Barcelona logró en las cuatro primeras décadas de este siglo mantener un alto nivel filológico y literario, y yo no dudo que la noble emulación que así se desarrolló entre Madrid y Barcelona contribuyó no poco al espléndido florecimiento del Centro de Estudios Históricos y del grupo de instituciones creadas alrededor de Menéndez Pidal: muchos créditos se consiguieron más fácilmente, se hicieron esfuerzos que por razones muy humanas se hubieran considerado, de otro modo, aplazables. Así es como florece la vida universitaria en Italia, Alemania y los EE. UU.: Florencia, Milán, Nápoles, etc. apenas son inferiores a Roma; Bonn, Leipzig, Munich, Viena no valen menos que Berlín, ni Chicago, Yale, Princeton, Chapel Hill, Berkeley y tantos más, valen menos que Harvard o Columbia. Pero finalmente se está realizando en España la proeza de ponerse al nivel de Francia (en lo malo no en lo bueno, claro), y se logró gracias al desastre del destierro en masa de universitarios catalanes; entonces se dio el golpe decisivo, y ahora la política oficial parece decidida a consolidar este resultado desastroso. En lugar de atraer a Madrid a todos los que valen, se deberían hacer esfuerzos para que vayan cuantos se pueda a otras Universidades: Madrid nunca escaseará de gente buena porque le sobran atractivos. Por lo menos, si se encuentra alguno con vocación para ir a otra Universidad, pese a las desventajas con que luchará siempre, no se deberían poner obstáculos a este deseo.

Le decía pues a don Ramón que mi deseo era tener una cátedra en Barcelona, no en Madrid. Después de escribir estos trece tomos de original de mi Diccionario Etimológico, como el que vio usted, es ridículo pensar que yo pueda desinteresarme o descuidar la filología castellana en el resto de mi vida. Y si en algo puedo ser útil para la obra filológica que se reali- 
za en Madrid, doce horas de tren o tres de avión no son obstáculo para que pueda trasladarme a ésa tantas veces al año como convenga. Sí lo es el tener que vivir en Chicago. Si yo lograra ganar una cátedra en Barcelona, y se considerara útil mi presencia en Madrid, desde luego empeño mi palabra en pasar ahí los cuatro meses de vacaciones veraniegas, y cuantas semanas del resto del año me dejase libre la Universidad de Barcelona. No ignoro que la vida en Barcelona es bastante más cara, y que aquí más difícil para el filólogo hacerse con sueldos suplementarios; lo compensaría con la facilidad que me dan mis amistades de aquí y mi familiaridad con el medio barcelonés; y el hombre no vive sólo de pan: la alegría de vivir en mi tierra, junto a mi familia (no tengo hijos, pero sí muchísimos sobrinos), y de luchar porque la juventud que veo crecer a mi alrededor no se convierta en una masa de muchachuelos ignorantes, sería para mí el mejor de los estímulos.

Con ocasión de mi visita ofrecía usted, con magnífica generosidad, prestarse a una división de su cátedra con el objeto de que yo pudiera tener una. Nunca le agradeceré bastante ese gesto. Al mismo tiempo — quizá movido por las razones que acabo de exponer o haciéndome cargo de mi estado de ánimo - sugería usted también la creación de una cátedra lingüística en la Universidad de Barcelona. Es evidente que [Antoni $\mathrm{M}^{\mathrm{a}}$ ] Badía Margarit, hombre al parecer inteligente (aunque sus lamentables trabajos toponímicos destruyen la buena impresión de otros) pero inexperto y autodidacto, no basta. Esto último, mi querido don Dámaso, es lo que hay que hacer, y así se lo decía a don Ramón.

Desde luego lo esencial es que yo pueda volver a España y dejar Chicago. Es muy importante que sea para enseñar en Barcelona. Pero es importantísimo que no se desperdicie la ocasión que nos brinda el buen estado de salud de don Ramón. En el caso (que Dios no quiera) de que no sea posible llamar a unas oposiciones para Barcelona, llámense para donde se quiera y déseme una ocasión de reincorporarme a la Universidad española. Esto es muy urgente. Tengo que volver a Chicago a fines de septiembre. Ya no es posible de aquí a entonces hacer unas oposiciones. Pero volveré en el trimestre de primavera, de abril a junio, y para entonces es preciso haber hecho algo. Si es indispensable que permanezca un poco más, quizá pueda lograrlo.

Si puede usted ayudar a don Ramón en sus gestiones a favor de estas gestiones mías, se lo agradeceré en el alma y toda la vida.

Mi felicitación entusiasta por su trabajo sobre el Tirant. Creo que es lo más inteligente que se ha escrito sobre este libro, y de lo mejor que hay en la obra de usted. Vi allí varias cosas que yo había pensado siempre, pero me asombró la cantidad de ideas nuevas, para mi y para todos, que desde entonces han pasado a enriquecer mi conocimiento de este gran libro.

Con un saludo atento le estrecha cordialmente las manos su amigo

P. D. Sería también importante que usted o don Ramón me dijeran cuál sería el mejor momento para que haga yo un viaje a Madrid antes de salir para América. Si es posible, para visitar al Subsecretario de Instrucción Pública, con miras a fijar la fecha de las oposiciones; si no, por lo menos para conocerlo o para visitar a ustedes dos más tranquilamente y acabar de ponernos de acuerdo. Creo que embarcaré en el Havre el 23 de septiembre. Díganme cuándo sería mejor que vaya a ésa. 